\title{
Las mujeres de Arturo Pérez-Reverte
}

\author{
Alexis GrohmanN \\ Universidad de Edimburgo
}

\section{RESUMEN:}

Los personajes femeninos en la literatura de Arturo Pérez-Reverte han suscitado poco interés académico. El presente estudio busca paliar esta carencia. Se analiza la figura de la mujer en la literatura revertiana en conjunto y de forma particular, a través de una selección representativa de personajes femeninos significativos y sus características principales mediante su aparición cronológica, haciendo especial hincapié en las novelas de la primera etapa novelística del autor, hasta $E l$ pintor de batallas. Así se observará cuán formidables son las mujeres en la literatura revertiana y lo superior al hombre que es la mujer en la cosmovisión revertiana en conjunto.

\section{PALABRAS CLAVE:}

Arturo Pérez-Reverte, mujer, personaje literario.

\begin{abstract}
:
Arturo Pérez-Reverte's female characters have attracted scant scholarly attention. This article attempts to address this shortcoming by analysing female figures in Pérez-Reverte's literature as a whole and also through a selection of significant female literary characters in chronological order of their appearance, with a special focus on the novels of the author's first period, which comes to an end with El pintor de batallas. What emerges is that female characters are formidable beings in Pérez-Reverte's literature and that the female gender as a whole is superior to man in his worldview.
\end{abstract}

\section{KEYWORDS:}

1Arturo Pérez-Reverte, woman, character.

Poco interés académico ha suscitado hasta ahora la figura de la mujer en la literatura de Arturo Pérez-Reverte, con la salvedad evidente de los estudios sobre La Reina del Sur que inevitablemente hacen hincapié en su protagonista Teresa Mendoza y un artículo sobre las mujeres en El club Dumas. ${ }^{1}$ El presente estudio busca paliar en alguna medida esta carencia. No pretende ser exhaustivo por razones de espacio y también porque busca centrarse al final en dos figuras femeninas en concreto que representan, a mi modo de ver, uno de los (varios) interesantes «tipos» de mujer que

\footnotetext{
${ }^{1}$ Jorge Zamora, «Femmes fatalelfemmes formidables: mimetismo y subversión en El club Dumas o La sombra de Richelieu de Arturo Pérez-Reverte», Anales de la literatura española contemporánea, vol. 33, nº 1 (2008), págs.153-173.
} 
moran en el mundo revertiano, entre otras razones porque mediante ellas se perfilan también las notables limitaciones de sus héroes masculinos. Empleo, dicho sea de paso, la palabra morar de forma consciente, porque implica un señorío y una elegancia generales que prácticamente todas las mujeres revertianas ostentan en mayor o menor medida, a diferencia de muchos de los hombres, como espero que se pueda ver. De este modo, después de considerar la figura de la mujer en la literatura revertiana en conjunto (con la excepción de la serie de novelas del capitán Alatriste, que por razones de extensión no se incluye en este trabajo) y de forma general, destacando una selección representativa de determinados personajes y sus características principales mediante su aparición cronológica (haciendo especial hincapié en las novelas de lo que se podría considerar la primera etapa novelística del autor, hasta $E l$ pintor de batallas), pasaremos a considerar este tipo concreto y sus particularidades.

La escasez de estudios de los personajes femeninos en el mundo revertiano no deja de resultar bastante llamativa por dos razones. Por un lado, no creo que sea atrevido afirmar que son pocos los autores masculinos contemporáneos que han concedido tanto protagonismo a la figura de una mujer que en su narrativa, invariablemente y a marcada diferencia de los personajes masculinos del mismo autor cartagenero, suele ser inteligente, independiente, sabia, libre y autónoma, enérgica y fuerte, y también seductora, no sólo notablemente en cuanto sirena o femme fatale (uno de sus tipos de mujer más destacados) -que también, a menudo-, sino en el sentido más amplio del término, es decir, como alguien que ejerce un atractivo fascinante, cautivador, poderoso sobre otros personajes y asimismo sobre el lector. Por otro lado, dado esto y en el contexto de un período donde hay feminismos cada vez militantes que a veces conducen a la condenación de la literatura de Pérez-Reverte como «machista», no deja de sorprender que ésta es y ha sido todo lo contrario, a juzgar por los papeles y la calidad literaria de sus protagonistas femeninos y por la igualdad de la mujer con los hombres en su mundo, o más bien la superioridad de aquélla, como, por ejemplo, arguye Zamora en el caso de los personajes de El club Dumas. El hecho de que a menudo las novelas revertianas estén ambientadas en mundos cuyos protagonistas suelen ser hombres o el punto de vista desde el que se narran sea masculino, se confunde quizás con la propia literatura y la cosmovisión que emerge en conjunto, que no creo que se puedan calificar como machistas. Es decir, se confunde la parte (la ambientación o la perspectiva) con el todo (la literatura en conjunto). De «machista», es decir, una literatura que desprende una actitud de prepotencia de los varones respecto a las mujeres $(D E L)$, sólo podría tildar la literatura revertiana quien la desconoce por completo; sus protagonistas femeninos desmienten del todo tal calificación, como espero que se pueda ver. 
En realidad, ni siquiera hay que haber leído sus novelas para saber que Pérez-Reverte, siempre que se ha referido a la mujer, ha defendido no tanto su igualdad con el hombre, cuanto, más bien, su franca superioridad. Basta con haber leído a lo largo de los años los frecuentes artículos que le dedica a la figura de la mujer tal como emerge tanto en la literatura como en la vida. Ciñémonos a modo de ilustración a uno de sus artículos más tempranosy representativos, escrito para el suplemento EL SEMANAL en 1994. «Mujeres de armas tomar», recogido luego por José Luis Martín Nogales en Patente de corso (1993-1998), pone las cosas en su sitio. El texto gira en torno a una pregunta que le hace al autor un asistente a un congreso y a la respuesta de aquél. La pregunta de por qué asigna a menudo «virtudes masculinas» a las mujeres en sus novelas obtiene una larga y enérgica réplica queresulta ser de lo más esclarecedora para la cuestión que nos concierne. Arturo Pérez-Reverte deja entrever que lo que para el asistente son virtudes exclusivamente masculinas -el valor físico, la independencia y la agresividad - para él no lo son, y explica que al asistente le chocaba que las mujeres de ficción revertianas «fuesen capaces de empuñar un florete, una pistola, pelear por su vida o por la de otros, conspirar e incluso asesinar, bajo palabras como amistad, amor, lealtad a un hombre o a una idea, e incluso honor personal». Y añade lo siguiente que reproduzco íntegramente porque compone una cosmovisión y una especie de manifiesto íntegros, además de la paleta en la que se mezclan los colores de los que se vale el autor para pintar a la mujer en su narrativa:

Le respondí que allá él con sus mujeres, pero que uno se honra con el trato de varias que son de armas tomar. Y que muchos nos negamos a aceptar que, por culpa del ridículo concepto medieval de la frágil dama como devocionario caballeresco, la mujer se perpetúe, en los relatos de ficción escrita o cinematográfica, reducida al papel de compañera o comparsa del viril protagonista [...] Y resulta que no. Que de virtudes masculinas y femeninas podríamos hablar un rato largo sin necesidad de irnos a Hollywood. Sin ir más lejos, esa mujer que madruga cada día y después de hacer la casa se va a la compra y vuelve para la comida y se sienta un rato a ver el culebrón y luego prepara la cena y deja, todavía, que el sábado el pariente le dé un asalto, es más dura de pelar, tiene más valor y más entereza que el animal de bellota que, en teoría, la mantiene.

Hagan memoria. Nadie resiste como una mujer la enfermedad, o el sufrimiento propio o ajeno: cuida a los enfermos, se crece en la adversidad, pare hijos -y a veces los concibe- con dolor; y sobre lealtades y sentidos del deber podría dar lecciones a muchos maridos. En cuanto a hacer daño, cuando una mujer abre la navaja no es, como la mayor parte de los hombres, para montar bulla y que nos vean, sino para matar de verdad. En el otro extremo, enamorada, es capaz de amar con más entrega y pasión, y de hacer cosas, tomar decisiones, que los hombres, tan razonables y formales que somos, ni soñaríamos 
siquiera. No hay quien detenga una mujer -ni familia, ni marido, ni convenciones sociales- cuando decide liarse la manta a la cabeza; y como adversario, nada más corrosivo para nuestra fatua virilidad que el odio o el desprecio de una hembra inteligente.

Pero, aparte de ser más consecuente y valerosa que los hombres, la mujer también es más culta. No se trata de más tiempo libre, como dicen algunos simples, sino de menos egocentrismo: curiosidad por el mundo exterior. La mujer posee mucha información global, porque ve más televisión, más cine. Lee más [...] Los hombres estamos demasiado ocupados haciendo números, tomando decisiones fundamentales, endureciendo el gesto ante el espejo, pobres desgraciados, alardeando de un temple que se derrumba en cuanto nos tocan la nómina o el estatus, mientras ellas parecen poseer una reserva secreta de entereza para sobreponerse, aunque caigan chuzos de punta.

Échenle un vistazo a las estadísticas. Además de su presencia en otros sectores, las mujeres copan las carreras de humanidades, o al menos lo que va quedando de éstas. Así, en este final de siglo que termina de tan mala manera, en la confusión que caracteriza a esta especia de noche que se nos viene encima, tan fría como esos ordenadores que engendran los hombres con microchips en lugar de espermatozoides, las mujeres pueden terminar siendo para la cultura lo que los monjes medievales fueron en la trinchera de sus monasterios mientras el mundo se desplomaba alrededor. Y ésa será su venganza, su revancha histórica sobre nuestra estupidez y nuestra injustificada autocomplacencia.

Virtudes masculinas, decía aquél. Permita que me ría, respondí. Ya quisiéramos nosotros, los hombres, poseer ciertas virtudes. ${ }^{2}$

No creo que sea necesario añadir mucho más. Sólo me permitiría apuntar que en España, hace casi 30 años, pocos escritores había que dibujaran y defendieran a la mujer de esta forma. Ahora hay muchos más que sí lo hacen, pero me atrevería a decir que más bien porque se ha puesto de moda hacerlo y porque es fácil quedar bien de esta manera, y además ayuda a blindarse y evitar ser tachado de machista. Pero cabe recordar que Arturo Pérez-Reverte lo lleva haciendo desde sus inicios como escritor, tanto en su prosa narrativa como en su prosa periodística. Y de esa forma seguirá dibujando -pero también defendiendo- a la mujer maltratada por los hombres, ${ }^{3}$ una y otra vez a lo largo de los años en sus artículos y en su narrativa. No

\footnotetext{
${ }^{2}$ Arturo Pérez-Reverte, «Mujeres de armas tomar», en Patente de corso (1993-1998), ed. de José Luis Martín Nogales, Madrid, Alfaguara, 1998, págs. 137-139.

${ }^{3}$ Véase, por ejemplo, un artículo de 1999, «Esas zorritas», en el que critica muy duramente a la justicia española por no castigar adecuadamente a los padres que violan a sus hijas (Arturo Pérez-Reverte, «Esas zorritas», en Con ánimo de ofender (1998-2001), ed. de José Luis Martín Nogales, Madrid, Alfaguara, 2001, págs. 99-101).
} 
sorprenderá, por tanto, la calidad y la naturaleza de la figura que empieza a despuntar en sus novelas.

\section{Las mujeres de Arturo Pérez-Reverte}

En su primera obra narrativa, la novela corta El húsar, «las mujeres eran algo muy remoto», como se dice en el propio texto, porque la novela se adentra en el horror que es la guerra (la Guerra de la Independencia en este caso) a través de su protagonista, el joven e idealista húsar Frederic Glüntz. ${ }^{4}$ No obstante, la figura de la mujer sí estará más o menos presente en cierto modo en El húsar, aunque de forma mucho más velada de lo que lo estará en todas las demás novelas de Arturo PérezReverte. En esta obra surge un primer tipo de mujer revertiana: en El húsar la figura de la mujer es el prototipo de la mujer evocada, como lo serán Nikon en El club Dumas u Olvido, en mucha mayor medida, en El pintor de batallas; es decir, tiene una presencia no directa sino mediada a través de la memoria del protagonista, cuyos recuerdos en realidad llegan a confirmar la ausencia definitiva de la mujer de la vida del protagonista (porque, por un lado, el recuerdo de por sí ya conlleva siempre la ausencia de lo recordado y, por otro, porque la mujer ya no forma parte de la vida del héroe); Nikon ha abandonado a Lucas Corso, Olvido se ha muerto y Claire Zimmerman queda irremediablemente atrás porque Frederic ha pasado a formar parte del mundo masculino de la guerra del cual no volverá.

Así Frederic explica que en este escenario, como por ejemplo en la «liturgia cerrada» del «ritual del escuadrón preparándose para la marcha, rumbo a la batalla inminente», la mujer «resultaba fuera de lugar» o, como mucho, sólo tiene un papel como objeto idealizado en los sueños del soldado: «Para nada hacía falta allí una presencia femenina. Si acaso, unos hermosos ojos como lejanos testigos del drama heroico, velados por dulces lágrimas al ser su linda poseedora puesta al corriente de los acontecimientos, al conocer la muerte del húsar». ${ }^{5}$ Es decir, la mujer queda excluida de este mundo particular: en este «rito del clan exclusivamente masculino [...] debía quedar excluida cualquier presencia del sexo opuesto». ${ }^{6}$ Del mismo modo en que quedaba excluida también del mundo de los templarios, recuerda a continuación el subteniente, en una referencia intertextual o de intertextualidad restringida (pues hay una alusión a otra obra del propio autor, por mucho que no llegara a publicarse) al acordarse de un libro sobre la historia de los caballeros templarios que había leído años atrás: «El mundo de los templarios era un mundo de hombres, del que las mu-

\footnotetext{
${ }^{4}$ Arturo Pérez-Reverte, Obra breve / 1, Madrid, Alfaguara, 1995, pág. 28.

${ }^{5}$ Ibíd., págs. 64-65.

${ }^{6}$ Ibíd., pág. 64.
} 
jeres quedaban excluidas por definición. El honor, Dios y la pelea eran sus únicos acicates». ${ }^{7}$ Con todo, esto no impide que de vez en cuando Glüntz evoque la imagen de Claire fugazmente hasta renegar de ella al final. ${ }^{8}$

De este modo, este modelo de mujer nos remite sutilmente al arquetipo de la mujer que representa los valores de lo «femenino luminoso» («the light feminine») asociados con la heroína arquetípica, según el formidable análisis de Las siete tramas básicas a lo largo de la historia de la literatura de Christopher Booker, sus arquetipos y las razones por las que contamos historias. Esa figura sería el anima (de derivación jungiana) cuyo papel consiste en representar valores como la simpatía por otros y la visión de la totalidad, cruciales para escapar de los límites impuestos por el ego y lograr la unidad con el propio ser.9 La realización última, la plenitud humana última se representa en las historias arquetípicas mediante la unión final del héroe («light masculine») con la heroína («light feminine»).

En el mundo de héroes cansados de Pérez-Reverte no se alcanzará nunca tal plenitud y unión (obviamente, en parte porque a finales del siglo XX y principios del XXI el mundo y la literatura, y la cosmovisión de nuestro autor en concreto, carecen de la pureza del alma y de la ingenuidad de los relatos arquetípicos, por mucho que se sigan perpetuando en algunos casos). Como mucho, en la literatura revertiana se evocará de forma velada una plenitud fugaz, disfrutada sólo temporalmente en un momento siempre pasado. Con todo, están presentes varios arquetipos, aunque matizados o pasados por un filtro finisecular), a los que se alude y con los que se juega. La distancia temporal, espacial o vital que separa a muchos protagonistas de las mujeres evocadas (p. ej. Claire en El húsar, Nikon en El club Dumas u Olvido en El pintor de batallas) solo pone en evidencia la imposibilidad del héroe cansado de conseguir la plenitud última -por ello estos héroes cansados puede que estén inspirados en parte en el arquetipo del héroe tradicional, pero también están alejados de él, adaptándose a las necesidades de un relato escrito a finales del siglo XX o principios del XXI que se inspira en los clásicos pero que carece en parte de su inocencia y pureza-, aunque esto no impide que los héroes cansados sí logren otras victorias.

Jaime Astarloa, el maestro de esgrima de la homónima novela siguiente, un temprano modelo del héroe cansado revertiano que vive fiel a sus reglas personales,

\footnotetext{
${ }^{7}$ Ibíd., pág. 65.

${ }^{8}$ «La imagen de Claire Zimmerman pasó fugazmente ante él, entre los recuerdos de la jornada que estaba viviendo, y no sin esfuerzo logró retenerla. Las notas musicales, creía recordar que de un clavicordio, volvieron a sonar, lejanas, en sus oídos. Ante él se inclinaba un delicado rostro de niña desde el que dos grandes ojos azules lo contemplaban con tímida admiración [...]» (ibíd., pág. 129; véanse también las págs. 149 y 175).

${ }^{9}$ Christopher Booker, The Seven Basic Plots. Why we tell Stories, Londres, Continuum, 2004, pág. 478.
} 
tendrá como antagonista a una nueva especie de mujer: Adela de Otero. Pero en la novela de 1988 también hay vestigios de la figura de mujer evocada, entre otras cosas porque «era imposible no encontrar una sombra agridulce de mujer en la memoria de cualquier hombre» (como vimos que era el caso en El húsar); luego también Astarloa «tenía la suya; pero de aquello hacía ya demasiado tiempo». ${ }^{10}$ Como en la vida de Frederic Glüntz, en la de Jaime Astarloa «hubo una vez una mantilla blonda bajo la que relucían dos ojos con brillo de azabache, y una mano blanca y fina que movía con gracia un abanico». ${ }^{11}$ Esta imagen es especialmente llamativa porque, aparte de retrotraernos a la mujer y al «oficial enamorado hasta la médula» que era el maestro de esgrima en su juventud, ${ }^{12}$ es una anticipación -también formalmente, en la composición mediante la sinécdoque en todos los casos- de la «mano delicada y blanca» apoyada en el marco de la ventanilla de una carroza, y «el rostro de una niña, unos cabellos rubios peinados en tirabuzones, y la mirada más azul, limpia y turbadora que he contemplado en toda mi vida» que componen las pinceladas del primer retrato de Angélica de Alquézar en El capitán Alatriste, aunque ésta, en honor a la verdad, lejos de representar a una heroína pura como indica su nombre, es de la estirpe de Milady de Los tres mosqueteros y por tanto nada menos que la encarnación del Diablo en palabras de Íñigo Balboa $;{ }^{13}$ y precisamente al Diablo nos referirá asimismo en gran medida el retrato de la mujer protagonista de El maestro de esgrima.

Adela de Otero es el primer villano y la primera sirena o femme fatale revertianos, la primera seductora de una larga estirpe que estará presente en muchas de sus novelas, y por tanto conviene prestarle especial atención. Como se sabe, femme fatale es el nombre que se dio a esa clase de mujer que tiene un papel protagonista en las novelas detectivescas hard-boiled de Raymond Chandler, James M. Cain y Dashiell Hammet y los films noirs de los años 30 y 40 que representan una sociedad corrupta, una prevaleciente oscuridad y cinismo, un caos moral y la corrupción de todos los valores morales, con unos protagonistas masculinos duros, cínicos y, a menudo, cansados veteranos de guerra ${ }^{14}$ La femme fatale seduce a un hombre para sus propios fines y puede producir su perdición, y en realidad me parece que no es sino una puesta al día de la figura mitológica de las sirenas, habitantes, en la Odisea de Homero, de una isla localizada entre Escila y Caribdis, que atraían y seducían a los marineros con sus cantos y hacían que estrellaran sus barcos contra la costa rocosa

\footnotetext{
${ }^{10}$ Arturo Pérez-Reverte, El maestro de esgrima, Madrid: Alfaguara, 1988 y 1999, pág. 43. Véanse también sus enamoramientos y duelos relacionados en París y Roma (ibíd., págs. 78-9).

${ }^{11}$ Ibíd., pág. 78.

${ }^{12}$ Ibíd., pág. 78.

${ }^{13}$ Arturo y Carlota Pérez-Reverte, El capitán Alatriste, Madrid, Alfaguara, 1996, págs.20 y 125.

${ }^{14}$ Véase David Cook, A History of Narrative Film, Londres, Norton, 1990, págs. 467-71.
} 
de la isla para luego devorarlos en su confusión. La sirena es una figura asociada con la muerte y representa desde la Antigüedad las tentaciones de la carne, los peligros del halago y de la seducción.

Adela de Otero, una «aventurera», es la encarnación de la sirena o femme fatale..$^{15}$ Con su hermoso rostro, sus grandes ojos «de color violeta con pequeñas irisaciones doradas» a los que sabe sacar partido, su boca carnosa y bien dibujada comparable a «un corte de cuchillo en una fruta de pulpa roja y apetecible» (analogía que connota sensualidad, pero también peligro), su enigmática sonrisa y su toque masculino (muchas de las mujeres revertianas, dicho sea de paso, tendrán un toque y atractivo andrógino, desde Irene Adler de El club Dumas hasta Eddie Mayo de Sabotaje), la cicatriz en la comisura derecha de la boca que le da un especial atractivo, es una «misteriosa» $\mathrm{y}$ «desconcertante mujer» que encierra algún «secreto fascinante» y que, según Astarloa, maneja las armas del encanto y la seducción; y es evidente, en su apreciación, «que no se trataba de la primera vez que ella recurría a aquellas armas». ${ }^{16}$ De ahí que logre que el maestro de esgrima se abandone a «un sutil juego de sentimientos recién recobrados». ${ }^{17}$ Exactamente como el encantamiento producido por el canto de las sirenas, de Adela de Otero «emanaba una extraña atracción que lo invitaba, dulce y peligrosamente, a confiarse cada vez más». ${ }^{18} \mathrm{El}$ maestro cae bajo su hechizo desde el principio y se enamora de ella, ${ }^{19}$ aunque no faltan las advertencias de peligro. Entre otras, la cicatriz de la mujer sugiere y prefigura «ecos de oscura violencia»; sus ojos violeta revelan un repentino «relámpago de cólera», cuando al principio el maestro se niega a enseñarle su célebre y fatal estocada de los doscientos escudos (estocada que, por cierto, no es sino una suerte de «botte de Nevers») ${ }^{20}$ Los rasgos de su letra escrita son «largos y aguzados como puñales», anticipando el puñal que le intentará clavar en la nuca al maestro en su combate final. ${ }^{21}$ Adela de Otero inmediatamente se convierte «en agresivo adversario» con un arma en su mano y un

\footnotetext{
${ }^{15}$ Arturo Pérez-Reverte, El maestro de esgrima, cit., pág. 149.

${ }^{16}$ Ibíd., págs. 57, 94, 62, 68-69, 101 y 165. Me atrevería a afirmar que es posible o probable que su nombre sea un compuesto del de la bisabuela de Arturo Pérez-Reverte, Adèle Replinger Gal y de Carolina Otero Iglesias, alias la Bella Otero, la famosa bailarina española de finales del siglo XIX y principios del XX.

${ }^{17}$ Ibíd., pág. 92.

${ }^{18}$ Ibíd., pág. 115.

${ }^{19}$ Ibíd., págs. 151 y 295.

${ }^{20}$ Ibíd., págs. 62 y 69. La «botte de Nevers» es la estocada secreta del duque de Nevers en uno de los folletines predilectos de Pérez-Reverte, Le bossu (El jorobado) de Paul Féval, que al principio a Henri de Lagardère le quita el sueño porque le resulta imposible de parar en su primer duelo con Nevers, aunque luego dice haber desvelado el secreto (Paul Féval, Le bossu, París, Hachette, 1997, págs. 71 y 74).

${ }^{21}$ Ibíd., pág. 171.
} 
tono que desprende un «eco de amenaza» y, sin sus zapatos de tacón (que se ha quitado para una sesión de esgrima), destila cierta «belleza animal», moviéndose como una gata. ${ }^{22}$

La influencia que llega a ejercer sobre Astarloa es «misteriosa y perturbadora» y más adelante se da cuenta de que lo ha manipulado «para algo que ignoraba, pero que no podía esforzarse en imaginar sin que lo estremeciese una irracional sensación de oscuro espanto». ${ }^{23} \mathrm{Y}$ si alguna duda le quedara al lector de que Adela de Otero ha embrujado a Astarloa como una sirena hecha y derecha, la confirmación la proporciona explícitamente el propio texto, justo en el instante previo a asestarle al maestro el golpe mortal clavándole el estoque, con la muerte dibujada en sus ojos: «Se le había ido acercando sin dejar de hablar, como una sirena que embrujase con su voz a los navegantes mientras el barco se precipitaba hacia un arrecife». ${ }^{24}$

La comparación de Adela de Otero con una gata no es casual: se insinúa reiteradamente en la novela ${ }^{25}$ y resulta ser precursora de otra analogía, la de la mujer sirena con el diablo, que se irá afianzando conforme se desarrolla la trama. La segunda analogía surge de forma natural de la primera, principalmente porque la forma de gato (negro) era la favorita adoptada por el demonio según superstición medieval, algo a lo que se alude en el texto cuando el maestro se cruza con algún que otro félido (por ejemplo: «El gato [...] clavó en el maestro de armas el recelo de sus ojos malignos»). ${ }^{26}$ De parecida manera, la propia Adela de Otero se irá asemejando al Maligno.

La presencia de lo diabólico va incrementando conforme avanza la novela, insinuándose o prefigurándose en primer lugar mediante el adjetivo «endiablado» y el adverbio «endiabladamente» empleados siempre en relación con la figura de Adela de Otero y, en segundo, mediante la situación que se ha producido a raíz de su presencia y actuación. Aunque en un par de ocasiones se usan adjetivos para describir un rasgo del propio Astarloa, quien maneja el florete «con diabólica destreza», y de Luis de Ayala, quien, al hablar justamente de Adela de Otero, sonríe en un momento dado «con aire mefistofélico», en todos los demás casos lo diabólico nos conduce a de Otero. ${ }^{27}$ Así, desde su primer encuentro con el maestro de esgrima, «todo resultaba endiabladamente insólito», algo que se repetirá con leves variaciones a lo largo de la novela para describir con matices demoniacos las circunstancias en que se ve

\footnotetext{
${ }^{22}$ Ibíd., págs.97, 101 y 106.

${ }^{23}$ Ibíd., pág. 206.

${ }^{24}$ Ibíd., pág. 347.

${ }^{25}$ Ibíd., pág. 343.

${ }^{26}$ Ibíd., pág. 194.

${ }^{27}$ Ibíd., págs.81 y 184.
} 
envuelto Jaime Astarloa. ${ }^{28}$ (La novela, aunque narrada en tercera persona, adopta el punto de vista del maestro). En su entrada en escena, De Otero ya es caracterizada como una «endiablada joven», «testaruda como el Diablo». ${ }^{29}$ Se revelará como una mujer sin escrúpulos y se comparará a una serpiente. ${ }^{30}$ Las analogías y asociaciones entre la mujer y el Diablo se multiplican en la segunda mitad de la novela. En una conversación con Astarloa, De Otero defiende al diablo citando a Byron: «El Diablo dice la verdad más a menudo de lo que se cree, pero tiene un auditorio ignorante». ${ }^{31}$ Se menciona la ópera Roberto el Diablo. Agapito Cárceles, el contertuliano de Astarloa torturado por los colaboradores de Adela de Otero que buscan recuperar las cartas comprometedoras que Cárceles le ayuda a descifrar al maestro una vez que De Otero ha asesinado a Luis de Ayala con la estocada de los doscientos escudos, le contesta agonizando a la pregunta del maestro sobre quién le hizo tanto daño: «El Diablo [...] Ellos son... el Diablo».32 En las últimas páginas Adela de Otero lisonjea a Astarloa diciéndole que le comentaron que se defendió como el mismísimo Lucifer cuando cruzó floretes con los malos; el maestro de esgrima ya no se deja halagar por la mujer: «Váyase al diablo». ${ }^{33} \mathrm{Y}$, a punto de clavarle el largo agujón en la nuca, habiéndolo hipnotizado con sus ojos y el vestido que se va desabrochando, la boca de Adela de Otero se contrae «en un intenso rictus, que la cicatriz de la comisura convertía en mueca diabólica» y poco después, en el combate final y fatal, esbozará una «maliciosa sonrisa», una «mueca de salvaje alegría» $\mathrm{y}$ «maligna». ${ }^{34}$

\footnotetext{
${ }^{28}$ Ibíd., pág. 70. Asimismo: «Todo aquello era endiabladamente absurdo»; «Todo aquello resultaba endiabladamente absurdo»; «Todo era endiabladamente absurdo»; «Todo aquello era endiabladamente grotesco» (ibíd., págs.. 77, 161 y 249).

${ }^{29}$ Ibíd., págs. 71 y 100.

${ }^{30}$ Ibíd., pág. 325.

${ }^{31}$ Ibíd., pág. 159.

${ }^{32}$ Ibíd., pág. 286.

${ }^{33}$ Ibíd., pág. 337. Mediante la misma locución verbal y fórmula, que hará suya Pérez-Reverte en su literatura, muy típica de folletines decimonónicos en especial -véase, sin ir más lejos, su uso en el arriba citado Le bossu (p.ej., «Au diable!, interrompit Saldagne» [Paul Féval, op. cit., pág. 61], uno de los espadachines amigos de Lagardère, que, por cierto, le prestará probablemente su nombre al Saldaña de Alatriste-, Astarloa expresará su desengaño y rechazo, en un pasaje idéntico en sus conclusiones a las líneas con las que termina El húsar: «Al diablo, fue la única conclusión a la que fue capaz de llegar. Al diablo con todos ellos. Ya era demasiado viejo para ir a esconderse como un gazapo» (ibíd..., pág. 306). (cf.: «Al diablo. Al diablo todos ellos con su romántica y estúpida idea de la guerra. Al diablo los héroes y la caballería ligera del Emperador. Nada de eso se sostenía a la luz de aquella terrible oscuridad» [Pérez-Reverte, El húsar, cit., pág. 175]; las cursivas son mías). Ambos pasajes aparecen en el mismo lugar de las respectivas novelas: en el clímax precedente al desenlace final; y representan el momento culminante de lucidez, toma de conciencia y (re)afirmación de la postura de los héroes cansados.

${ }^{34}$ Arturo Pérez-Reverte, El maestro de esgrima, cit., págs. 343-345 y 350-351.
} 
De este modo se estrenan los elementos diabólicos en la novelística revertiana, en la que retornarán con endemoniada insistencia. Su presencia es significativa, porque, por un lado constituye un eficaz elemento de literatura gótica y también folletinesco que caracterizará muchas de sus novelas, mediante el cual se rinde además homenaje a textos de los que se nutre; por otro, a través de la asociación de la mujer-sirena Adela de Otero con lo diabólico se confirma su papel arquetípico de «dark feminine» o de «femineidad oscura», que es lo femenino cuando, detrás de una (engañosa) exhibición de atributos «femeninos», es motivado por el egocentrismo asociado con la «masculinidad oscura», por valernos de la terminología de Christopher Booker. Al hablar del arquetipo de la trama de la Búsqueda («the quest») - un arquetipo del que se sirven muchas novelas revertianas, dicho sea de paso-, Booker explica que el segundo peligro que el héroe de esa trama tiene que afrontar es el de la Tentación (el primero es el Monstruo), que a menudo involucra a una hermosa y cautivadora mujer que, como vimos en El maestro de esgrima, hechiza al héroe como las sirenas, apunta Booker (entre otros ejemplos que da de la Odisea), que nos proporciona la imagen -la de la sirena- más completa de las formas que puede adoptar esa Tentación.

La esencia de la Tentación, en la síntesis que presenta Booker, es que le ofrece al héroe la promesa de una gratificación física, que puede ser sexual, comida o vino con efectos embriagadores, o simplemente un tiempo de tregua apacible y placentera que contrasta con la ardua tarea que ha de realizar. ${ }^{35}$ Uno de los ejemplos más antiguos sería la tentadora ninfa Calipso que detiene en su isla a Ulises y le impide volver a Ítaca durante siete años (Homero). Rendirse ante una Tentación puede resultar tan letal como una confrontación con el Monstruo, y la Tentación tiene mucho en común con el Monstruo, excepto que éste amenaza al héroe con una confrontación directa, mientras que aquélla procura conducirlo a su destino funesto mediante las artimañas de la astucia y la seducción; las sirenas son depredadoras bajo otro disfraz como hemos podido ver. ${ }^{36} \mathrm{Y}$, por lo demás, las sirenas pasaron a formar parte del propio bestiario de Satanás, junto con animales felinos y serpientes, entre muchas otras criaturas, así que todas las comparaciones que se establecen entre Adela de Otero y tales criaturas se encaminan al mismo fin.

Las mejores y más logradas representantes de lo «femenino oscuro» en la literatura serán capaces de retar al héroe tanto mediante las artimañas de la Tentación

\footnotetext{
${ }^{35}$ Christopher Booker, op. cit., pág. 74.

${ }^{36}$ Véase Christopher Booker, op. cit., pág. 74-5. La larga lista de todos los animales del bestiario de Satanás que nos proporciona Adso de Melk en su descripción de la intrincada portada de la iglesia de la abadía en El nombre de la rosa de Umberto Eco es un muy buen y completo ejemplo, por no alejarnos del tipo de literatura que nos concierne en el presente estudio (Primer día, Sexta; Umberto Eco, El nombre de la rosa, Barcelona, Lumen, 1988, pág. 58).
} 
como a través de la confrontación directa del Monstruo, como es el caso de Adela de Otero, quien se vale tanto de sus dones de atracción y seducción como, cuando estos fallan, del florete (y la aguja) en el cara a cara final para matar a Jaime Astarloa. En esta unión de sirena tentadora y monstruo, Adela de Otero es descendiente directa de Lady de Winter, la Milady de Alejandro Dumas, quien despliega una gran variedad de armas y facetas de carácter que hacen que más de una vez, como la propia de Otero, sea comparada explícitamente con animales felinos (pantera, tigre, león), serpientes, y, en suma, el Maligno. En palabras de Athos en el capítulo de la ejecución de Milady (el capítulo LXVI de Los tres mosqueteros), Milady no es una mujer, no pertenece a la condición humana, sino que es un demonio escapado del infierno. ${ }^{37}$ Aunque puede que Adela de Otero no llegue a cometer tantos actos diabólicos como Lady de Winter -como se recordará, aparte de las conspiraciones e intrigas que maquinó, Milady envenenó a una mujer en Béthune, arruinó y envenenó al hermano de Lord de Winter, engañó y deshonró a Athos, y asesinó al Duque de Buckingham y a Felton-, sí conspiró con su protector, engañó a Astarloa, asesinó a Luis de Ayala, ordenó torturar y matar a Agapito Cárceles y se dispone a dar muerte al maestro de esgrima. A la luz de todo eso, el hecho de que Adela de Otero esté en realidad motivada por una lealtad a una persona, su benefactor, no la convierte en menos diabólica y monstruosa en la descripción textual que hemos trazado arriba, aunque sí es cierto que, como argumenta Elvezio Canonica, la actuación de Adela de Otero «obedece a un sentimiento noble: el reconocimiento hacia su benefactor» y que eso la hace una figura atractiva, compleja y ambigua. ${ }^{38}$ Sea como fuere, es una mujer formidable. Las mujeres revertianas, si se alían con el Mal, si actúan con crueldad o pertenecen a lo «femenino oscuro», es a menudo por una serie de códigos a los que son fieles, por lealtad, bien a una persona (o su memoria), como en el caso de de Otero, bien a una idea.

El ajedrecista Muñoz de la siguiente novela, La tabla de Flandes, ha sufrido con anterioridad también a manos de una sirena cuando acude a él la protagonista Julia para que la ayude a imponer orden en el cuadro cuyo valor simbólico se ha de interpretar mediante reglas que se convertirán asimismo en reglas de detección (ya que para Muñoz todo es cuestión de una lógica común a un ajedrecista y un detective, en lo que se acabará convirtiendo muy a su pesar). Como observa Julia, en Muñoz son perceptibles «los estragos que sólo podemos causar las mujeres»y, en

\footnotetext{
${ }^{37}$ Alexandre Dumas, The Three Musketeers, Londres, Penguin, 2006, pág. 659.

${ }^{38}$ Elvezio Canonica, «"La virtud no es rentable": el combate a punta desnuda entre dos sistemas de valores en El maestro de esgrima», Territorio Reverte, Ensayos sobre la obra de Arturo Pérez-Reverte, editado por José Manuel López de Abiada y José Belmonte Serrano, Madrid, Verbum, 2000, págs. 75-88.
} 
concreto, esas «mujeres capaces de desmontar con minuciosidad de relojero los resortes que mueven a un hombre»..$^{39}$ (Por cierto, Roger de Arras, uno de los caballeros representado en el cuadro, muere precisamente porque es víctima, en su caso mortal, de la atracción de la mujer fatal, que es Beatriz de Borgoña [la dama negra del cuadro y de la doble partida, ajedrecística y vital que se libra por aquel entonces], ya que fue «atraído por el mudo canto de sirena que empuja a los hombres a darse de boca con su destino») ${ }^{40}$ Con todo, Muñoz «no sentía compasión ni desdén» para consigo mismo, «sino una especie de solidaridad desengañada y comprensiva». ${ }^{41}$

Julia, el primer personaje principal femenino de novela revertiana (de aparición temprana, si se considera que La tabla de Flandes es sólo su segunda novela, o su tercera si se incluye la novela corta El húsar), está restaurando un cuadro que plantea un enigma que la obliga además, no sólo a resolver un asesinato cometido en el siglo XV, sino a solucionar varios enigmas y crímenes (directamente vinculados al cuadro y a la partida de ajedrez representada) que se van produciendo a su alrededor en el Madrid de los años 80, que incluyen el asesinato de su ex novio y de una amiga suya, la lasciva e impúdica galerista Menchu Roch, un pintoresco personaje secundario. Emergerá de su aventura desengañada pero más lúcida, más dura y más fuerte, como había previsto César, que había urdido la trama entera para emocionar a Julia como cuando era niña y como prueba que le sirviese de aprendizaje, porque César era consciente de que su presencia en la vida de Julia le «había impedido siempre volar sola». ${ }^{42} \mathrm{Al}$ final, Julia conseguirá volar sola y emergerá más lúcida, dura y fuerte, después de armarse de valor para enfrentarse a la persona amenazadora que la cita por la noche en la Sala Doce del desierto Museo del Prado en lo que llama una «singular partida de caza», declarando de forma melodramática y folletinesca que «ella, Julia, había matado piratas» y que, por tanto, no iba a ser

un títere asustado sobre un tablero de ajedrez, sino alguien muy capaz de devolver, a la primera ocasión, ojo por ojo y diente por diente. Fuera quien fuese, si la quería encontrar, iba a hacerlo. En la Sala Doce o en el infierno. Por los clavos de Cristo que sí. ${ }^{43}$

\footnotetext{
${ }^{39}$ Arturo Pérez-Reverte, La tabla de Flandes, Madrid, Altea/Taurus/Alfaguara, 1990, págs.196, 211.

${ }^{40}$ Ibíd., pág. 190.

${ }^{41}$ Ibíd., pág. 196.

${ }^{42}$ Ibíd., pág. 384.

${ }^{43}$ Ibíd., pág. 340. De acuerdo con el tono autorreflexivo y dramático que ha marcado, respirará «hondo antes de entrar en la sala como había visto hacer en las películas» (ibíd., pág. 341).
} 
En aquella Sala Doce, se dará de cara con el cuadro El triunfo de la Muerte del «brutal Brueghel» ${ }^{44}$ y quedará desengañada en un violento y conmovedor relámpago de lucidez, al anticiparse la pérdida de todas sus ilusiones infantiles (que se hará definitiva en el capítulo siguiente cuando descubren a su querido César como el artífice del dédalo trágico) delante de un cuadro que lo revela todo acerca del mundo, un mundo visto como paisaje bélico que no es sino el paisaje del mundo en el enfrentamiento de la humanidad contra los ejércitos de la muerte, en breve escena de enfrentamiento de hombre, cuadro y desengaño que prefigura El pintor de batallas. Esta escena es una clásica bajada a los infiernos. ${ }^{45}$

La visión del Brueghel no abandonará a la mujer protagonista, que seguirá bajo su encantamiento y le proporcionará la mirada, la clave para el cuadro de Van Huys, sobre el cual lo imaginará superpuesto, ya que el de Brueghel lo contiene y lo explica todo, a ella incluida:

Todo se conjugaba en aquella escena terrible y definitiva, donde iban a parar, sin distinción en la suerte del último dado que rodaba sobre el tapete de la tierra, belleza y fealdad, amor y odio, bondad y maldad, esfuerzo y abandono. La propia Julia se había reconocido, también, en el espejo que fotografiaba con despiadada lucidez la ruptura del Séptimo

\footnotetext{
${ }^{44}$ Ibíd., pág. 355 .

${ }^{45}$ «Aquella pintura [...], siempre había ejercido sobre ella una peculiar fascinación. El acento trágico que inspiraba hasta la última pincelada, la expresividad de sus infinitas figuras sacudidas por el aliento mortal e inexorable, las numerosas escenas que se integraban en la macabra perspectiva del conjunto, habían, durante muchos años, excitado su imaginación. La débil claridad azul del techo destacaba los esqueletos que brotan en tropel de las entrañas de la tierra como un viento vengativo y arrasador; los incendios lejanos que recortan negras ruinas en el horizonte; las ruedas de Tántalo que giran en la distancia al extremo de sus pértigas, junto al esqueleto que, alzando la espada, se dispone a descargarla sobre el reo de ojos vendados que ora de rodillas... Y en primer término, el rey sorprendido en mitad del festín, los amantes ajenos a la hora final, la sonriente calavera que bate los timbales del Juicio, el caballero que, descompuesto por el terror, aún conserva el coraje suficiente para, en postrer gesto de valor y rebeldía, extraer su espada de la vaina, dispuesto a vender cara su piel en el último combate sin esperanza... » (Ibíd., pág. 343). Para Marina Mariani, en una sugerente interpretación, la bajada de Julia a la Sala Doce del Prado representa una clásica bajada a los infiernos, aunque Mariani se equivoca cuando dice que a Julia, a diferencia de Ulises, Eneas o Dante, «no le es posible sacar una lección más profunda de su viaje», ya que sí la saca como vamos viendo (Marina Mariani, «Arturo Pérez-Reverte: La tabla de Flandes (1990)». La dulce mentira de la ficción vol. II. Ensayos sobre la literatura española actual, ed. por Hans Felten y Agustín Valcárcel, Romanistischer Verlag, 1998, págs. 249-258). Mariani también observa que en la verdadera Sala Doce del Museo del Prado no se encuentran las obras mencionadas sino Las Meninas de Velázquez, «cuya construcción formal refleja el carácter multiplicador del texto» (ibíd., pág. 256); con la reordenación de 2010 resultado de la ampliación arquitectónica del museo, la colección Velázquez se distribuyó en siete salas y Las Meninas permanece en la Sala Doce.
} 
Sello del Apocalipsis. Ella era la joven vuelta de espaldas a la escena, absorta en sus ensueños, aturdida por la música del laúd que tañía una sonriente calavera. ${ }^{46}$

Y mediante el cuadro de Brueghel se efectúa el desengaño que viene con la pérdida de esperanzas e ilusiones y la lucidez adquirida; Brueghel arrasa los sueños de la infancia y sus vestigios:

En aquel sombrío paisaje ya no quedaba espacio para piratas ni tesoros escondidos, las Wendys eran arrastradas debatiéndose entre la legión de esqueletos, Cenicienta y Blancanieves olían el azufre con ojos desencajados por el miedo, y el soldadito de plomo, o San Jorge olvidado de su dragón, o Roger de Arras con la espada medio fuera de la vaina, ya no podían hacer nada por ellas. Demasiado tenían con intentar inútilmente, por un prurito de mero honor, asestarle un par de estocadas al vacío antes de enlazar sus manos, como todos los demás, con los descarnados huesos de la Muerte que los arrastraba en su danza macabra. ${ }^{47}$

En cierta medida es en este cuadro en el que se adentrará toda la narrativa revertiana -y no solo El pintor de batallas-, al indagar en la condición humana con lucidez y narrarnos un proceso de desengaño experimentado por el ser humano, como es el caso de la protagonista de La tabla de Flandes, a quien no le queda, a lo sumo, como al caballero del cuadro, sino resistir en vano con la espada en mano, por una cuestión de honor, de pie, un ser humano que, ello no obstante y por otro lado, no se resiste a jugar el juego dispuesto en el tablero de ajedrez (tanto literal como figurado). Entre esos dos polos, la vida reducida a una batalla descarnada contra la muerte y, a la vez, la vida como juego, se debaten no sólo los personajes femeninos revertianos, sino toda la narrativa en conjunto de Arturo Pérez-Reverte. ${ }^{48}$

De forma metanarrativa y autorreflexiva y con debido distanciamiento, porque ha quedado desengañada ya en su paso por la Sala Doce, y porque «era demasiado tarde, y por primera vez Julia no sentía deseos de escuchar», la restauradora de arte alcanzará una madurez como persona y también como personaje novelesco revertiano femenino al describir también el desenlace de la historia y su papel en ella, con la debida frialdad adquirida por «una curiosidad estrictamente formal. Estética». ${ }^{49}$ Así

\footnotetext{
${ }^{46}$ Ibíd., pág. 344.

${ }^{47}$ Ibíd., pág. 344.

${ }^{48}$ Sobre esta cuestión, se puede consultar asimismo mi libro, del que me he valido en parte para la confección del presente artículo (Alexis Grohmann, Las reglas del juego de Arturo Pérez-Reverte, Murcia, EDITUM, 2019).

${ }^{49}$ Ibíd., pág. 352.
} 
explicará como «su deber era hallarse presente, a un tiempo protagonista y coro, actor y público de la más fascinante tragedia clásica -todos estaban allí, Edipo, Orestes, Medea y los demás viejos amigos- que nunca nadie había creado ante sus ojos». ${ }^{50}$

Y al cerrar la puerta después de despedirse de César, quien se suicidará (en vez de esperar la justicia y la muerte por causa del SIDA -recuérdese que la novela se escribió en los años ochenta-), no sin antes haberles dejado una fortuna a Julia y Muñoz, caerá el telón metanarrativamente sobre esta historia principal «igual que si todo estuviera previsto de antemano y cada uno hubiese interpretado a conciencia el papel asignado en la obra». ${ }^{51}$ Y Julia, que ha vivido toda su vida y esta historia en que se vio envuelta como representación y juego, emerge como el primer personaje femenino de cierta enjundia y complejidad. A diferencia de Adela de Otero, que por su configuración y grado de individualidad, aparece más como un personaje tipo, con un conjunto de rasgos psicológicos y morales reconocibles como peculiares de un modelo ya configurado en cierta medida por la tradición, Julia emergerá como un personaje femenino fuertemente individualizado. Es más, por su gradación jerárquica en el desarrollo de la acción, y de modo diferente a Adela de Otero, que es antagonista, Julia emerge como el primer personaje femenino protagonista en la narrativa revertiana. Por último, por su génesis y desarrollo, es un personaje que evoluciona a lo largo de la obra, y por su grado de complejidad se puede argüir que es el primer personaje femenino «redondo», dotado de la «incalculabilidad de la vida de su entorno», con considerables ambigüedad y riqueza psicológicas. ${ }^{52}$

Las mujeres de la siguiente novela constituyen un variado y original abanico de personajes femeninos, creados por un autor cada vez más seguro de sí y de sus medios, mediante una miríada de juegos librescos e intertextuales o interdiscursivos. Makarova es una lesbiana dueña del bar que frecuentan Lucas Corso y Flavio La Ponte, dura pero también sentimental. Liana Taillefer es la viuda que asume explícitamente el papel de Milady de Winter en la trama urdida por Boris Balkan para la recuperación teatral del manuscrito que antes había estado en posesión de su marido Enrique Taillefer, un nuevo y lúdico modelo del tipo revertiano de femme fatale, intérprete avezada de Los tres mosqueteros, que, de hecho, despliega una lectura feminista de la novela de Dumas con Milady como la verdadera heroína, y que es también explícita e intertextualmente equiparada no solo con la antagonista de d'Artagnan, sino con otras dos clásicas femmes fatales del cine noir: las actrices Kim Novak y

\footnotetext{
${ }^{50}$ Ibíd., pág. 352.

${ }^{51}$ Ibíd., pág. 412.

${ }^{52}$ Véanse las observaciones de Demetrio Estébanez Calderón sobre el término «Personaje» (Demetrio Estébanez Calderón, Diccionario de términos literarios, Madrid, Alianza, 2008, pág. 830-832).
} 
Lana Turner. ${ }^{53}$ Pero el personaje femenino más sugerente, enigmático y seductor es, indudablemente, Irene Adler, la chica misteriosa y poco locuaz que acompañará a Corso a lo largo de su aventura. Es asimismo, a mi modo de ver, uno de los personajes femeninos más originales, logrados y memorables de Arturo Pérez-Reverte.

Irene Adler es una especie muy particular de héroe y «soldado cansado», mercenario solitario desde hace mucho tiempo, que en un principio busca mantenerse al margen «igual que si estuviera allí sólo de paso» y únicamente interviene con aportaciones decisivas cuando resulta absolutamente necesario. ${ }^{54}$ Adler intercambia signos de reconocimiento con Corso cuando entablan diálogo por primera vez en el tren camino de Sintra, en un juego intertextual de lectores cómplices que les permite reconocerse como habitantes de una patria (cultural) que tienen en común, como miembros de una cofradía secreta, que no es sino un juego a escala, si se quiere, del juego que representa El club Dumas en su totalidad: una partida intertextual o interdiscursiva de lectores cómplices que permite jugar y reconocerse como habitantes de la misma patria literario-cultural. ${ }^{55}$

Irene Adler viaja «desde hace siglos» y carga consigo un cansancio igualmente viejo. Parece ser nada menos que «el diablo enamorado» como le explica a Corso, una reencarnación de la Biondetta de Le Diable amoureux de Jacques Cazotte, como se especifica clara y metanarrativamente. ${ }^{56} \mathrm{Es}$, en parte, la necesaria presencia diabólica para este tipo de narración o juego como se explica en el Capítulo V. ${ }^{57} \mathrm{Su}$ función es cuidar de Corso y asegurarse de que recorre el camino a salvo ${ }^{58}$ y como heroína contemporánea se mostrará tan inteligente y dura como los hombres, tanto mental

\footnotetext{
${ }^{53}$ Arturo Pérez-Reverte, El club Dumas o La sombra de Richelieu, Madrid, Alfaguara, 1993, págs. 45, 166 y 367.

${ }^{54}$ Ibíd., págs. 138, 250, 388 y 465.

${ }^{55}$ Las alusiones son al Orient Express y la vieja Europa cosmopolita filtrados por el imaginario cultural de la literatura y el cine (ibíd., pág. 182).

${ }^{56}$ Ibíd., págs. 230, 287 y 289; Jacques Cazotte, Le Diable amoureux et autres écrits fantastiques, Paris, Flammarion, 1979. Véase también la cita de la novela de Cazotte que proporciona el epígrafe del Capítulo VII y el ejemplar de la obra de Cazotte que Adler le regala a Corso y que comentan (ibíd., págs. 177 y 273-4). Sobre las correspondencias entre Adler y Biondetta véanse los comentarios de José Perona en sus dos ensayos titulados «Historias de libros en La tabla de Flandes, El club Dumas y La piel del tambor de Arturo Pérez-Reverte, con una apostilla sobre el capitán Alatriste», en Espejos de una biblioteca, Murcia, KR, 1997, págs. 265-286 e «Historias de libros en tres novelas de Arturo Pérez-Reverte», en Territorio Reverte, Ensayos sobre la obra de Arturo Pérez-Reverte, editado por José Manuel López de Abiada y José Belmonte Serrano, Madrid, Verbum, 2000, págs. 368-388.

${ }^{57}$ Ibíd., pág. 139.

${ }^{58}$ Ibíd., págs. 250 y 467.
} 
como físicamente, no sólo capaz de competir con ellos, sino de vencerlos; $;{ }^{59}$ es por tanto y paradójicamente una figura que no representa la oscuridad sino todo lo contrario, una «light figure» hasta cierto punto, en la terminología de Booker, una figura que representa la lucidez y que ayuda al héroe a alcanzar el conocimiento, héroe con el cual incluso permanece unida al final, como observa acertadamente José Perona al resaltar una de las diferencias entre el diablo de Cazotte y el de Pérez-Reverte: «A diferencia de lo que ocurre con el texto de Cazzote [sic], se quedará con él cuando el infierno haya consumido en la desesperación las inútiles y sin embargo mediáticamente abrumadoras ansias contemporáneas de poder creer». ${ }^{60}$

Con sus «inquietantes ojos verdes y el cabello castaño muy corto» resulta muy hermosa, como se explica en la novela: «Guapa chica, habría dicho Flavio La Ponte»; «Endiabladamente bonita, habría dicho sin duda Flavio La Ponte». ${ }^{61}$ Por cierto, esta formulación indirecta, mediada -Corso dice que Irene Adler es guapa mediante una cita conjeturada de La Ponte- es un buen ejemplo, a muy pequeña escala, de la postmodernidad de El club Dumas, si nos atenemos a la definición que da Umberto Eco en sus «Apostillas a El nombre de la rosa»:

Pienso que la actitud posmoderna es como la del que ama a una mujer muy culta y sabe que no puede decirle «te amo desesperadamente», porque sabe que ella sabe (y que ella sabe que él sabe) que esas frases ya las ha escrito Liala. Podrá decir: «Como diría Liala, te amo desesperadamente». En ese momento, habiendo evitado la falsa inocencia, habiendo dicho claramente que ya no se puede hablar de manera inocente, habrá logrado sin embargo decirle a la mujer lo que quería decirle: que la ama, pero que la ama en una época en que la inocencia se ha perdido. ${ }^{62}$

Corso evita la falsa inocencia de decir sencilla y directamente que era una chica guapa citando a su amigo La Ponte, como Pérez-Reverte evita decir que Irene Adler es el diablo sin más, remitiéndonos a Cazotte y reconociendo que «el mío es un Lucifer de segunda mano», literario. ${ }^{63}$ La postura de Corso y de Arturo PérezReverte en El club Dumas a gran escala es postmoderna en el sentido en que se

\footnotetext{
${ }^{59}$ Véase Booker sobre esta nueva mujer que surge en el cine y la literatura de las últimas décadas del siglo XX (Booker, op. cit., pág. 486).

${ }^{60}$ Perona, «Historias de libros en La tabla de Flandes, El club Dumas y La piel del tambor», cit., págs. 276-7.

${ }^{61}$ Arturo Pérez-Reverte, El club Dumas, cit., págs. 131, 180 y 252. Aquí reaparece el adverbio que tan insistente y significativamente se empleó en El maestro de esgrima.

${ }^{62}$ Umberto Eco, «Apostillas a El nombre de la rosa», en El nombre de la rosa, Barcelona, Lumen, 1990, pág.659.

${ }^{63}$ Pérez-Reverte, El club Dumas, cit., págs. 287-288.
} 
incita a volver a visitar el pasado «con ironía, sin ingenuidad», ${ }^{64}$ puesto que, como nos recuerda también Boris Balkan explícitamente en la obra revertiana, «ya no hay lectores inocentes». ${ }^{65}$ De este modo, ninguno de los lectores o «interlocutores se sentirá inocente, ambos habrán aceptado el desafío del pasado, de lo ya dicho que es imposible eliminar; ambos jugarán a conciencia y con placer el juego de la ironía... Pero ambos habrán logrado una vez más hablar de amor» ${ }^{66}$ Así nos hablará PérezReverte del amor por los libros de aventura (y de otros) y de la aventura de los libros. Pero nos estamos desviando.

Es por ello y por el homenaje a Sherlock Holmes que Irene Adler está domiciliada en 221B de Baker Street, Londres, y que lleva el nombre de quien para el detective victoriano no es nada menos que la mujer suprema, «the woman» $\mathrm{O}$ «La Mujer» ${ }^{67} \mathrm{La}$ joven lee Las aventuras de Sherlock Holmes en el tren camino de Sintra y remite a Corso a la historia origen de su nombre, la primera de la colección; ${ }^{68}$ y más adelante, en una notable escena amorosa, es descrita físicamente como la suma de todas las mujeres: «Todas las mujeres, todas las hembras creadas por el género humano estaban allí, resumidas en aquel cuerpo de dieciocho o veinte años». ${ }^{69}$ Tiene sus propias reglas personales de juego y «códigos singulares». ${ }^{70}$ Irene Adler es en cierta medida el supremo héroe cansado revertiano, ya que en su caso se ha rebelado contra Dios y ha luchado con arcángeles, y está condenada a alcanzar la lucidez que «se paga con la inocencia del alma», que no es sino la lucidez que ostentan todos los héroes cansados revertianos fruto de su experiencia. ${ }^{71} \mathrm{Y}$ como Corso y todos los demás héroes revertianos, después de su batalla particular que ha perdido, porque la lucidez «no vence jamás», Irene Adler vive en un mundo desolado y frío, de hecho, el mundo más desolado y frío imaginable. ${ }^{72}$ Y quizás por ello le resulta lo suficientemente grato o sugerente el contacto humano que le proporciona Corso como para quedarse a su lado al final de la novela. Es un atisbo del calor o contacto humano que en algún

\footnotetext{
${ }^{64}$ Eco, op. cit., pág. 659.

${ }^{65}$ Pérez-Reverte, El club Dumas, cit., pág. 457.

${ }^{66}$ Eco, op. cit., pág. 659.

${ }^{67}$ Pérez-Reverte, El club Dumas, cit., págs. 184 y 279. Es como empieza «A Scandal in Bohemia»: «To Sherlock Holmes she was always the woman. I have seldom heard him mention her under any other name. In his eyes she eclipses and predominates the whole of her sex» (Arthur Conan Doyle, «A Scandal in Bohemia», en The Adventures of Sherlock Holmes, Londres, Penguin, 1981, pág. 9).

${ }^{68}$ Pérez-Reverte, El club Dumas, cit., págs. 180 y 183.

${ }^{69}$ Ibíd., pág. 361.

${ }^{70}$ Pérez-Reverte, El club Dumas, cit., pág. 244.

${ }^{71}$ Pérez-Reverte, El club Dumas, cit., pág. 468.

${ }^{72}$ Pérez-Reverte, El club Dumas, cit., págs.468-9.
} 
momento han tenido todos los héroes revertianos, Corso incluido, y que a veces añoran con dulce o amarga nostalgia. Pero sobre esto volveremos más adelante.

Las protagonistas de la siguiente novela, La piel del tambor, forman parte de otro club, un «insólito» y «extraño club» de quienes defienden una iglesia. ${ }^{73}$ Macarena Bruner, su madre, la Duquesa del Nuevo Extremo Cruz Bruner, y la hermana restauradora Gris Marsala son el trío de mujeres con las que se las tiene que ver el enviado especial del Vaticano, Lorenzo Quart.

Macarena y Cruz Bruner son los últimos miembros de una familia aristocrática en vías de extinción que hacen frente al poder vulgar del presente: a los banqueros cínicos, a la corrupción política y eclesiástica, a los nuevos ricos y a los peligros del olvido.

La duquesa del Nuevo Extremo Cruz Bruner, es consciente de que «es la penúltima de su estirpe» y librará la batalla por salvar la iglesia de otro modo. ${ }^{74}$ Con su larga memoria, la septuagenaria es superviviente de otros tiempos y mundos, mujer de cuyo molde quedan muy pocas, como reconoce Quart. ${ }^{75}$ Resume su situación del siguiente modo elocuente: "Yo también pertenezco a una especia amenazada: la aristocracia». ${ }^{76} \mathrm{Su}$ mundo es el que vimos evocado ya en El club Dumas durante la visita de Lucas Corso a Víctor Fargas, cuando se nos advirtió que «con las viejas familias pasa lo que con las civilizaciones: un día se agostan y mueren». ${ }^{77}$ Cruz Bruner sentencia que «ciertos mundos no terminan con terremotos, ni estrépitos formidables [...]. Se limitan a extinguirse en silencio, con un discreto ay». ${ }^{78}$ Se rinde ante la evidencia de que el dinero ha cambiado de manos y es de los advenedizos; «las grandes fincas son de los bancos y de los financieros [...]. Gente lista enriquecida en cuatro días, como pretende hacer mi yerno». ${ }^{79}$ Vistos desde esta perspectiva, los mensajes

\footnotetext{
${ }^{73}$ Arturo Pérez-Reverte, La piel del tambor, Madrid, Alfaguara, 1995, págs. 317 y 410.

${ }^{74}$ Ibíd., pág. 433.

${ }^{75}$ Ibíd., págs. 428-9.

${ }^{76}$ Ibíd., pág. 430.

${ }^{77}$ Arturo Pérez-Reverte, El club Dumas, págs. 188-9.

${ }^{78}$ Ibíd., pág. 430.

${ }^{79}$ Ibíd., pág. 310. De hecho, hay otro personaje femenino muy menor en la novela, la Niña Puñales (forma parte de un trío que se pone al servicio de Pencho Gavira y su socio para encauzar el negocio de la Iglesia), que es también representante de otro mundo en extinción. La Niña Puñales, el Potro del Mantelete y Don Ibrahim son más que los meros personajes burlescos, caricaturescos y cómicos a que la crítica los ha reducido; son la memoria de la otra España, la «que toda la chusma de empresarios y críticos y vil gallofa había terminado empeñándose en no reconocer», como se dice de la Niña Puñales; son «España por los cuatro costados; no la del folklore barato y facilón para turistas y castizos de pastel, sino la otra, la de verdad»; son «la memoria dramática de un pueblo que echaba las penas cantando y los diablos empalmando navajas desesperadas»; son los derrotados de una «España ingrata que también tenía lugares como Sevilla» (ibíd., págs. 294-295). Por ello, el final de la Niña Puñales
} 
que Vísperas envía al Vaticano ya nos dan pistas sobre la identidad del pirata, que no se desvela hasta el final, puesto que «el mundo y las ideas a las que apelaba el pirata informático había dejado de existir hacía mucho tiempo». ${ }^{80}$ Sólo quedan algunos vestigios de este mundo, como los últimos guerreros de la estirpe, su memoria y la vieja guardia revertiana fiel de siempre que no abandona su puesto cuando la guerra está perdida, «los cuadros de barniz oscuro que montaban guardia secular en las sombras de la Casa del Postigo». ${ }^{81}$

Al final de la novela, la elegante y algo pícara duquesa se revela orgullosamente como miembro del «exclusivo club» de los piratas informáticos, y su actuación como el misterioso hacker Vísperas no se describe sino en términos de juego, un juego noble, eso sí, cuyas cartas el Vaticano busca descubrir, el atrevido y peligroso juego de una septuagenaria que, con el apodo de «Reina del Sur» (apodo que obviamente anticipa el de una mujer protagonista revertiana bien distinta), y «con sentido del humor», desde la mesa de su Casa del Postigo en Sevilla pone «en jaque al Vaticano»; Cruz Bruner se ha convertido en una experta informática que se divierte terriblemente..$^{82}$ La duquesa comparte mucho con el hacker que se infiltra «por puro placer, por la emoción del juego», como nos explica Pérez-Reverte en un artículo sobre un hacker del año 1994, «Un héroe de nuestro tiempo», un pirata informático de dieciséis años que comparte el gusto por la Coca-Cola de la duquesa, hecho este último que quizás se pueda interpretar como la única pista, por incongruente en la anciana, que se proporciona en la novela sobre la identidad de Vísperas. ${ }^{83}$ Será ese juego suyo lo que conducirá al Vaticano a enviar a Quart a investigar el caso.

La hija de la duquesa emplea unas armas distintas a las de su madre, pero a estas alturas conocidas en el mundo revertiano: las de la seducción. En un principio y antes de conocer a Macarena, Quart hace frente a la tentación de la mujer, frente al «antiguo ritual de la intimidad» entre hombres y mujeres, con una «autodisciplina desconsolada, dolorosa». ${ }^{84}$ En un contexto en el que la indulgencia de los superiores de la Iglesia está asegurada, dejando el asunto de faldas, por así decir, «a la discreción moral y a la inteligencia de cada protagonista», la castidad consiste para Quart

y los demás vencidos por esa España moderna que ya no tiene sitio para ellos, cuando de nuevo caen derrotados, es el de quienes se resignan con dignidad a su destino en una escena en que se tiene presente y se celebra el mensaje intertextual que esencialmente encierra y que no es otro que el consuelo de «We'll always have Sevilla» (ibíd., págs. 540-2).

${ }^{80}$ Ibíd., pág. 390.

${ }^{81}$ Ibíd., pág. 586.

${ }^{82}$ Ibíd., págs. 262, 259, 384 y 577-580.

${ }^{83}$ Arturo Pérez-Reverte, «Un héroe de nuestro tiempo», en Patente de corso, Madrid, Alfaguara, 1998, págs. 48-50.

${ }^{84}$ Arturo Pérez-Reverte, La piel del tambor, cit., pág. 115. 
«en pecado de orgullo antes que en virtud; pero así era la regla en torno a la que ordenaba su vida»; porque

el templario con la espada como único apoyo bajo un cielo sin Dios necesitaba apelar a la regla, si quería afrontar con dignidad el retumbar de la caballería sarracena acercándose a lo lejos, desde la colina de Hattin. ${ }^{85}$

Pero la fuerza de voluntad que mantiene su disciplina, su tranquilidad de templario y su fidelidad a las reglas flaqueará ante el deseo despertado por la Mujer. ${ }^{86} \mathrm{Ma}-$ carena Bruner, en el análisis de Gris Marsala, es una huérfana como el propio Quart, «una huérfana que se aferra a los restos de su naufragio», porque «heredó un mundo que ya no existía». ${ }^{87}$ No en vano su situación se evoca literaria, metanarrativa o interdiscursivamente con referencia a dos novelas clásicas del siglo XX, de Thomas Mann y Giuseppe Tomasi di Lampedusa respectivamente, que nos narran el ocaso de viejas acomodadas o aristocráticas familias europeas, como «el efecto Buddenbroock [sic]: la conciencia de un mundo que se extingue, la tentación gatopardesca de aliarse con los advenedizos para sobrevivir. La desesperanza de la inteligencia». ${ }^{88}$ Resignada a su destino de mujer sin hijos, se aferra a su lucha por la iglesia y la historia de su antepasada.

El epígrafe del Capítulo VI, en el que la hija de la duquesa entra en escena, una cita de La flecha de oro de Joseph Conrad, es inequívoco al respecto: «En usted están todas las mujeres del mundo» ${ }^{89} \mathrm{Al}$ describirse como la suma de todas las mujeres, la caracterización de este personaje femenino se solapa con la de Irene Adler en El club Dumas y apela claramente a un arquetipo. Macarena Bruner, mujer de rompe y rasga de acuerdo con la clásica locución coloquial, representa también a la Mujer, especialmente en el aspecto de tentadora, de sirena o femme fatale, un tipo o lado de mujer que en la narrativa revertiana vimos que tiene sus orígenes en la Adela de Otero de El maestro de esgrima. Así, Bruner encarnará a la Mujer en cuanto «instrumento del Maligno, faro de perdición, enemiga del género humano y del alma inmortal» en términos genéricos, en los dos sentidos de la palabra, es decir en términos generales y en tanto que representante de su sexo. ${ }^{90}$ Por eso, Quart intuye

\footnotetext{
${ }^{85}$ Ibíd., pág. 252.

${ }^{86}$ Ibíd., pág. 271.

${ }^{87}$ Ibíd., pág. 407

${ }^{88}$ Ibíd., pág. 407; Buddenbrooks: Verfalleiner Familie (1901) e Il Gattopardo (1958) son las novelas en cuestión. Hay también otras alusiones indirectas a El Gatopardo (véase el Capítulo V. de Alexis Grohmann, Las reglas del juego de Arturo Pérez-Reverte, cit.).

${ }^{89}$ Ibíd., pág. 221.

${ }^{90}$ Ibíd., pág. 344.
} 
que le resultaría peligroso prescindir de su uniforme o cota de malla de cura en la cena con ella. ${ }^{91}$ Con las piernas de rigor en tales casos - «demasiado largas y bien torneadas para la tranquilidad espiritual de cualquier cura»-, con su atractiva risa franca de muchacho (otro ejemplo de un elemento andrógino, componente frecuente en los personajes femeninos revertianos), con sabiduría «vieja de siglos», aureolada por los estímulos sensoriales de una Sevilla encantadora, Macarena Bruner, en tanto que sirena y una de esas «criaturas abominables, Salomé, Jezabel. Invención del Maligno», entonará el canto que hechizará a Quart y hará que éste esté dispuesto a arrancarse «el alzacuello de la camisa, volviendo atrás para tomarla en sus brazos como los oficiales que destrozaban su carrera en brazos de mujeres fatales». ${ }^{92}$ Bruner quizás no destruya su carrera del todo, pero la suspenderá, dado que Quart optará por ponerse de parte del club del padre Ferro que defiende la iglesia y se verá alejado del IOE y del Vaticano. Este club incluye a Macarena, cuya meta es precisamente ésta, usar «el sexo como un arma de batallas para ganarse al cazador de cabelleras», en palabras de José Perona. ${ }^{93}$

Porque Macarena Bruner, rica y hermosa aristócrata andaluza, separada de su ambicioso marido (que se quiere hacer con el terreno de la iglesia) porque ella quería un hijo y él no, es también una suerte de soldado librando su propia batalla, «una batalla contra el tiempo y el olvido» en sus propias palabras. ${ }^{94}$ Ha convertido la defensa de la iglesia en una cuestión personal, una obligación que ha recaído sobre ella a través de la figura de su antepasada Carlota Bruner y su hermosa y trágica historia; aparte de femme fatale, tiene por tanto también algo de heroína romántica, como observa su madre. ${ }^{95}$ «Me limito a librar mi guerra personal, a defender mi espacio», insiste;

cuando finalice, me encogeré de hombros y aceptaré que llegue el final con la conciencia tranquila; a la manera de esos soldados que sólo se rinden tras disparar el último cartucho. Después de haber cumplido con el apellido que llevo y con las cosas que amo. Eso incluye Nuestra Señora de las Lágrimas y el recuerdo de Carlota. ${ }^{96}$

Éste es su juego y sus reglas. Y ese juego incluye la seducción y conversión de Lorenzo Quart a su causa. Después de la noche que pasa con Macarena, Quart será aún más cansado; no le guarda rencor, puesto que se ha «dejado utilizar con plena

\footnotetext{
${ }^{91}$ Ibíd., pág. 222.

${ }^{92}$ Ibíd., págs. 239, 247, 371 y 573.

${ }^{93}$ José Perona, «Historias de libros», cit., 382.

${ }^{94}$ Arturo Pérez-Reverte, La piel del tambor, cit., pág. 368.

${ }^{95}$ Ibíd., págs. 369 y 432.

${ }^{96}$ Ibíd., pág. 369.
} 
conciencia; él era un arma tan adecuada como otra cualquiera, y para Macarena resultaba legítimo pelear por una causa que creía justa», pero le quedará «el vacío de la pérdida, debidamente atenuado por el orgullo y la disciplina» y en su interior sólo encuentra «la nada más absoluta. Un cansancio largo, objetivo, resignado, inexpresable de otro modo que no fuese una mirada, o una sonrisa». ${ }^{97}$

Después de las «largas horas de paz y combate» entre ellos, que es como se condensa su episodio amoroso, Quart no sabe si «acababa de condenar su alma, o de salvarla». ${ }^{98}$ La magia devastadora de la sirena lo ha perdido:

Perdido, según había dicho Macarena con extrema precisión poco antes de obrar en su carne el sombrío milagro. Porque estaba escrito: Ella destruirá tu corazón y tu volun$\mathrm{tad}$. Y las viejas escrituras eran sabias. La exquisita, inocente maldad vinculada al poder destructor de toda mujer, incluía dejar al otro la lucidez necesaria para contemplar los estragos de su derrota. Y a Quart le bastaba para verse enfrentado a la propia condición, involucrado a su pesar, desprovisto para siempre de coartadas con que apaciguar la con-

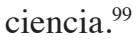

La Mujer, el formidable personaje femenino revertiano, vencerá al hombre. Y Quart se perfilará como héroe plenamente cansado y soldado derrotado. ${ }^{100}$ Pero esto no es todo: puede que haya traicionado al soldado, pero es posible que en el trayecto no haya condenado su alma, sino que la haya salvado, por adelantar una respuesta a la pregunta que se hace. En los instantes previos a dar el paso definitivo, rindiéndose ante Macarena, al pasar una noche en compañía de una mujer, y al bajar su defensa, se abre un resquicio tanto en la narración, como en la conciencia de Quart en un párrafo largo y lírico con el que termina el undécimo capítulo, pasaje en el cual se parece sugerir el principio de una reconciliación entre el niño que fue Quart y el cura adulto, entre él y los fantasmas de un pasado que lo han ido persiguiendo a lo largo de la novela y de su vida. ${ }^{101}$

En la novela posterior se afianzará y se profundizará la relación entre mujer y sirena que se viene forjando en las novelas revertianas desde Adela de Otero. En La

\footnotetext{
${ }^{97}$ Ibíd., págs. 572-3.

${ }^{98}$ Ibíd., págs.480-1.

${ }^{99}$ Ibíd., pág. 488.

100 «Todo era una trampa ancha y vieja, con ese río tranquilo por donde discurría el tiempo que nada respeta, o que confirma tarde o temprano la condición de los hombres. Que arrastra las banderas de los buenos soldados» (ibíd., pág. 517).

${ }^{101}$ Ibíd., pág. 468. Este asunto lo abordo en mi libro Las reglas del juego de Arturo Pérez-Reverte, cit., y también lo estudiaré en una conferencia en un congreso que organiza la Cátedra Arturo Pérez-Reverte sobre la obra de nuestro autor en Toulon en diciembre de 2019.
} 
carta esférica, el héroe cansado y más o menos lúcido, el marino Coy, se las tendrá que ver con Tánger Soto, cual héroe griego que se tiene que enfrentar a una travesía decretada por los dioses: «Ése, concluyó resignado» al cruzarse con la mirada de Tánger, «era el verdadero periplo que le había dispuesto Atenea». ${ }^{102}$ Tánger Soto es quien tiene «las claves del viaje», porque es ella la que ha seducido a Coy con su canto de sirena; pero Coy es un Ulises que «no tenía tripulantes a quienes taponar los oídos, ni nadie que lo amarrara al palo para resistir a las voces que cantaban en los arrecifes» en su regreso a Ítaca. ${ }^{103}$ Por ello sucumbe al canto y encanto de la sirena, «jodido, fascinado y solo». ${ }^{104}$ Aunque, desde el principio, como se anticipa ya en el juego proléptico con el que se señala su primer encuentro con Tánger, ${ }^{105}$ es plenamente consciente de que se está metiendo en un lío, como él mismo reconoce; es decir, acepta, sabe, que será engañado. ${ }^{106}$

Tánger Soto -con ese nombre del puerto y la ciudad al otro lado del estrecho de Gibraltar (en donde está ambientada una parte de la novela), tan milenaria como Cartagena, frecuentada como ésta por fenicios, griegos, romanos, bizantinos y españoles, entre muchos otros, internacionalizada hasta su incorporación a Marruecos- es la encantadora que seduce al marino. Es la sirena revertiana más plena y minuciosamente desarrollada.

La identificación se produce explícitamente desde el comienzo de la novela, cuando Coy, después de toparse con ella en Barcelona durante la subasta del Atlas marítimo de las costas de España de Urrutia Salcedo, joya cartográfica del siglo XVIII -el desencadenante de la historia- que es adjudicada a la mujer, en la casa Claymore (guiño intratextual que nos remite a La tabla de Flandes), y de salvarla del acoso de Nino Palermo que también quería hacerse con el Urrutia, viaja a Madrid y se presenta inesperadamente ante Tánger alegando que ella lo ha atraído como las sirenas: «"Las sirenas", dijo de pronto. [...]. "Cantaban, dice Homero. Llamaban a los marinos, ¿verdad?... Y ellos no podían evitarlo"». ${ }^{107}$ Tánger es a la vez la encarnación moderna de la sirena, la femme fatale del cine noir (en una estrecha conexión que también hemos trazado en mujeres protagonistas de anteriores novelas y que es

\footnotetext{
${ }^{102}$ Arturo Pérez-Reverte, La carta esférica, Madrid, Alfaguara, 2000, pág. 199.

${ }^{103}$ Ibíd., págs. 172 y 199.

${ }^{104}$ Ibíd., pág. 172.

105 «Luego estimó rumbo y abatimiento. Si a algo estaba acostumbrado era a calcular por instinto ese tipo de cosas; aunque la última vez que se había ocupado de trazar una derrota -nunca mejor dicho, lo de derrota- ésta lo hubiera llevado directamente hasta un tribunal naval» (ibíd., pág. 24).

${ }^{106}$ Como reconoce, «uno sabe que hay rocas delante [...] no se deja engañar. Lo sabe» (ibíd., págs. 114 y 171).

${ }^{107} \mathrm{Al}$ final de la obra se la compara de nuevo a una «extraña sirena» (ibíd., págs. 78 y 541).
} 
de nuevo puesta de manifiesto en la presente): es Kim Basinger (en L.A. Confidential), es Jessica Rabbit, es Lauren Bacall, es Brigid O'Shaughnessy o Mary Astor. ${ }^{108}$

O'Shaughnessy y Astor no se nombran, dicho sea de paso, pero ésta es la actriz que interpreta el papel de aquélla en la película The Maltese Falcon (la versión dirigida por John Huston en 1941), basada en el libro de Dashiell Hammet del que Tánger atesora una primera edición de $1930 ;{ }^{109}$ y, por tanto, cuando Tánger mantiene que el barco «es mi halcón maltés» se identifica con O'Shaughnessy-Astor. En cuanto a Bacall, no se menciona título, pero la película en que ella representó el prototipo de la femme fatale es The Big Sleep (de 1946), cuya trama, por cierto, era tan complicada que no la comprendían ni siquiera su director y guionistas, entre éstos William Faulkner, según su propia admisión. ${ }^{110}$ Por cierto, hay correspondencias entre la trama de La carta esférica y la novela de Dashiell Hammet y su adaptación cinematográfica de 1941, no sólo a través de la presencia de la famme fatale y del héroe cansado (Sam Spade/Coy) en ellas, sino también mediante el hecho de que en The Maltese Falcon, el «McGuffin» (por emplear el término acunado por Alfred Hitchcock) en torno al cual gira la trama consiste en un halcón maltés de oro cubierto por joyas que los templarios de Malta enviaron en 1539 a Carlos V y que desaparece de la faz de la tierra cuando unos piratas se hacen con el barco que transporta el tesoro, exactamente lo que sucede con el tesoro del Dei Gloria que constituye el «McGuffin» de La carta esférica. Y estas conexiones se establecen explícitamente cuando Tánger se refiere al Dei Gloria como su «halcón maltés». ${ }^{11}$

El juego de claridad y sombras del cabello de Tánger es anticipatorio y anuncia una relación sinecdóquica con el hecho de que se trata de un personaje de claroscuros. ${ }^{112}$ Desde el principio se pone en evidencia que Tánger, como toda femme fatale, se está aprovechando astutamente de Coy para su propios fines egoístas. ${ }^{113}$ Y Coy sabe que con «la melodía extraña que trazaba en el silencio», la sirena Tánger, «muy lista, o tal vez intuitiva hasta lo enfermizo, con un riguroso sentido de los meca-

\footnotetext{
${ }^{108}$ Ibíd., págs. 301, 402 y 468.

${ }^{109}$ Ibíd., págs. 89-90.

${ }^{110}$ Véase David Cook, A History of Narrative Film, New York, W. W. Norton, 1990, pág. 334.

${ }^{111}$ Arturo Pérez-Reverte, La carta esférica, cit., pág. 301.

${ }^{112}$ Ibíd., pág. 301. Este efecto es común en Pérez-Reverte y recuerda, por ejemplo, el de «la luz de la vidriera emplomada, descompuesta en rombos de color» que «arliqueneaba» la chaqueta de César en La tabla de Flandes, prefiguración que encierra una pista temprana sobre la personalidad de quien resulta que despliega un juego intrincado en el cual desempeña como actor varios papeles (Arturo Pérez-Reverte, La tabla de Flandes, cit., pág. 127).

${ }^{113}$ En un momento dado, Coy «imaginó que se volvía loco y que la seguía hasta el faro del fin del mundo entre vientos y naufragios, y que ella pretendía algo más que utilizarlo a secas» (Arturo PérezReverte, La carta esférica, cit., pág. 105).
} 
nismos que rigen a los hombres», lo tiene en su poder, pese a escuchar el marino «el inequívoco rumor del mar en las rocas peligrosamente próximas». ${ }^{114}$ Coy queda «atrapado, tragándose el trocito de queso hasta el alambre. Cling. Chas»; porque, en otra metáfora revertiana empleada más de una vez a lo largo de su literatura, se trata del tipo de mujeres «que desmontan para siempre el mecanismo de hombres hechos y derechos con un gesto, una mirada o una simple palabra», y por quienes, «en otros tiempos [...], los hombres mataban o arruinaban sus fortunas, vidas y reputación». ${ }^{115}$ En otras palabras, Tánger es «una maldita bruja mala», como le espeta Coy adelantada la novela y se revelará efectivamente en el desenlace. ${ }^{116}$

Tánger seduce, pues, a Coy. Lo hace no tanto con «su apariencia singular, atractiva y casi adolescente», pese a rozar los treinta años, su media melena de cabello rubio dorado, liso y perfecto, sus ojos azules de reflejos oscuros, iris azul marino y las miles de minúsculas pecas que le cubren la cara y el cuerpo enteros como irá comprobando «con delicioso estupor Coy»-que también-,${ }^{117}$ cuanto con su atractiva y enigmática personalidad -impredecible y sorprendente como el jazz-, con el «hastío europeo»con el que a veces ríe (lo que le da a ella también un elemento de héroe cansado, dicho sea de paso), aunque también tiene una risa simpática de chico (de nuevo el toque andrógino) «al que sientes deseos de acercarte, intuyendo que puede ser buen compañero de juego, o de aventuras», su «línea de vida muy larga, como si hubiera vivido muchas vidas», los Players sin filtro que fuma, su biblioteca y sus Tintínes (a los que volveremos), su labrador Zas (con el cual Coy trabará una amistad silenciosa pero tan verdadera y profunda que quedará hondamente afectado por su asesinato, tanto que al final será lo único que no le perdonará a la mujer), y con sus rasgos o toques masculinos y soldadescos en los que se hace hincapié, que dibujan por tanto a Tánger como un cruce entre la sirena y el soldado, que para Coy ya es -«Eres una especie de soldado, entonces»- porque trabaja para la Armada (la Sección de Investigación y Adquisiciones del Museo Naval de Madrid, para ser exactos): el reloj masculino de acero que lleva en la muñeca derecha, grande y de esfera negra; el padre soldado (un militar que llegó a coronel); su «camisa masculina, militar»; su saco militar («un auténtico saco de dormir del ejército»); su chapa de identificación de soldado; o su «endiabladamente agresiva» firmeza. ${ }^{118}$ No sorpren-

\footnotetext{
${ }^{114}$ Ibíd., págs. 211, 256 y 288.

${ }^{115}$ Ibíd., págs. 86, 170 y 281 .

${ }^{116}$ Ibíd., pág. 429.

${ }^{117}$ De hecho, las pecas le fascinan a Coy y vuelve a referirse a ellas a lo largo de la novela, y cuando Piloto le pregunta qué busca de ella, Coy contesta: «Quiero contarle las pecas, Piloto»; lo que éste interpreta sin rodeos: «Comprendo. Quieres tirártela» (Ibíd., pág. 334).

${ }^{118}$ Ibíd., págs. 22-23, 37, 74, 82, 89-90, 117, 139, 169, 185-6, 250 y 420.
} 
de, dada toda la cantidad de rasgos que no se corresponden con los de su sexo, que cuando de pequeña veía sus adoradas películas de vaqueros quisiera «ser soldado y llevar el rifle». ${ }^{119}$

Tánger también seduce a Coy con su historia del barco y del tesoro. Ella considera esa historia, el barco y el tesoro exclusivamente suyos porque son la culminación de toda su vida, como le deja muy claro al marino, introduciendo ese nexo explícito con la novela de Dashiell Hammett y su famosa adaptación cinematográfica que ya mencioné arriba:

Esa era mi historia [...]. Estaba destinada a mí, y toda mi vida, mis estudios, mi trabajo en el Museo Naval, me encaminaban a ella antes de que yo misma lo supiera [...]. Para mí es el sueño de toda una vida. [...] El Dei Gloria me pertenece [...]. Y nadie me lo va a quitar. Es mi halcón maltés. ${ }^{120}$

No es, por tanto, en absoluto desencaminada la analogía con Ahab que se establece en la novela. El sonido del martillazo imaginado y también metafórico de una Tánger que clava su doblón de oro español en la madera del mástil de un barco como recompensa para Coy si descubre el Dei Gloria («clic, clac»), la hermana con el capitán del ballenero Pequod en Moby Dick que lo ofrece como premio para quien aviste la ballena blanca en el Capítulo XXXVI de la obra de Herman Melville a la que se rinde extenso homenaje en la de Pérez-Reverte.La misma onomatopeya, «Clic, clac. Clic, clac», se usa para los pasos que da Tánger en la habitación arriba de la de Coy imaginada como Ahab con su pata de hueso de ballena en la cubierta de arriba -estas onomatopeyas contribuyen a establecer el nexo que une a Tánger con Ahab y la convierten a ella en una especie de Ahab en su búsqueda monomaníaca y letal del barco, mientras Coy ya ha sido identificado con Ismael en el minidrama escenificado, y el marino «nunca había soñado, en ninguno de sus barcos y libros y puertos y vidas anteriores e inocentes, un Ahab tan seductor arrastrándolo a navegar sobre su tumba»- ${ }^{121}$ La obsesión con el barco de Tánger es tan monomaníaca y, por lo tanto en última instancia tan destructiva y mortal, como la de Ahab con la ballena blanca. Por eso entra y sale de la vida de Coy sin que éste llegue a poseerla nunca, como él mismo se percata. ${ }^{122} \mathrm{Y}$ no juega limpio.

Pero Tánger también hechiza a Coy hablándole de la importancia de Tintín en su vida, cuya colección de aventuras completas ocupa un lugar privilegiado en su

\footnotetext{
${ }^{119}$ Ibíd., pág. 169.

${ }^{120}$ Ibíd., pág. 301.

${ }^{121}$ Ibíd., pág. 252.

${ }^{122}$ Ibíd., pág. 507.
} 
biblioteca. ${ }^{123}$ Cuando Tánger le explica que su descubrimiento de la existencia e historia del Dei Gloria «se parecía a eso que a veces sueñas cuando niña. El mar, el tesoro...», echa mano de Tintín para dilucidar los orígenes del encanto de la historia $-\mathrm{y}$, a la vez, se manifiesta metanarrativamente parte de la inspiración de la trama de La carta esférica- ${ }^{124} \mathrm{y}$ va rejuveneciendo en el proceso:

Parecía distinta, más joven, cuando se levantó y fue hasta los libros del anaquel: [...] sus ojos eran más azul marino que nunca y parecía sonreír cuando vino de regreso a la mesa con dos álbums de Tintín: El secreto del Unicornio y El tesoro de Rackham el Rojo. [...] Entonces ella, que abrazaba los dos álbums contra el pecho, se echó a reír, y parecía una mujer muy diferente al hacerlo. Se echó a reír franca, alegremente, y luego dijo: mil millones de mil rayos..$^{125}$

Por medio de Tintín, sueños y horizonte se juntan en la vida de Tánger, y ella rescata su infancia hasta que la mujer y la niña que fue se funden. En las dos páginas que siguen, Tánger le explica a Coy el papel primordial de Tintín en su vida: la dedicación maniática con la que ahorraba para comprarse estos álbumes de niña; cómo «todavía, al abrir un Tintín, puedo sentir ese aroma que a partir de entonces asocié con la aventura y la vida»; cómo en Tintín «todavía es posible la aventura»; cómo Tintín es responsable de su obsesión por la historia del Dei Gloria; cómo la viñeta de El tesoro de Rackham el Rojo en la que Tintín, vestido de buzo, se acerca «caminando por el fondo del mar al pecio impresionante del Unicornio hundido» marcó su vida de forma decisiva; cómo, junto con algunas películas y algunos otros libros, «estos álbums formatearon para siempre el disquete de mi infancia»; en suma, cómo estas aventuras de Tintín y del capitán Haddock se convierten en la maqueta simbólica a través de la cual vive gran parte de su vida. ${ }^{126}$ Es hablando de Tintín con Coy que éste puede observar no sólo el fervor, la devoción por el mundo creado por Georges Remi, sino también la concomitante recuperación de la niña que se va efectuando delante de sus ojos:

Había apoyado la punta de los dedos sobre la página con una delicadeza extrema, como si temiera alterar los colores. Coy, que no miraba el álbum sino que la miraba a ella,

\footnotetext{
${ }^{123}$ Ibíd., pág. 90.

${ }^{124}$ Remito al lector a Las reglas del juego de Arturo Pérez-Reverte, cit., donde he explorado las correspondencias entre estas aventuras de Tintín y la trama de El club Dumas y La carta esférica en particular.

${ }^{125}$ Ibíd., pág. 128-9.

${ }^{126}$ Ibíd., págs. 130-1.
} 
comprobó que seguía sonriendo, ausente, con aquel gesto que la rejuvenecía hasta darle la misma expresión que la muchacha abrazada por su padre en la foto del marco. Un gesto feliz, pensó. De esos que todavía tienen el contador a cero. Más allá estaba la copa de plata abollada y falta de un asa. Campeonato infantil de natación. Primer premio. ${ }^{127}$

Estas páginas están entre las más importantes y reveladoras de la novela: no sólo porque las aventuras de Tintín se presentan como la patria del alma de Tánger y por la evidencia de que Tintín condiciona su vida entera y su búsqueda del Dei Gloria, y condiciona por tanto también La carta esférica en su conjunto (es una de sus claves principales, junto con La isla del tesoro), además de representar por consiguiente una forma lúdica de vivir la vida; sino también porque en estas páginas Arturo PérezReverte revela la estima que siente por la figura de la Mujer al tributarla con el mayor reconocimiento posible: le presta al personaje femenino una parte inequívoca de su bios

\section{-Tánger es Pérez-Reverte-.}

En estas pocas páginas que giran en torno a Tintín, nos está hablando Arturo Pérez-Reverte de su propia infancia y la brumosa tierra natal de su alma, porque lo que se reproduce en estas pocas páginas de La carta esférica palabra por palabra las más de las veces no es sino lo que nos ha relatado ya con anterioridad Pérez-Reverte a propósito de la publicación de la biografía de Hergé escrita por Pierre Assouline en 1996, en su columna del 1 de marzo de 1998 recogida más adelante también en Los barcos se pierden en tierra («Siempre al oeste»). ${ }^{128}$ Es decir, Arturo Pérez-Reverte nos cuenta en las mismas palabras que luego le prestará a Tánger cómo «aquellos Tintínes formatearon para siempre el disquete de mi infancia», cómo condicionaron su vida entera, cómo vivió y vive su vida a través del prisma de las aventuras de Tintín, ideas que reiterará con variaciones en otras dos columnas sobre la importancia capital de las aventuras de Tintín en su vida, tituladas «Mil millones de rayos» $\mathrm{y}$ «El viejo amigo Haddock», las tres recopiladas en Los barcos se pierden en tierra. En La carta esférica, Tánger, exactamente como Pérez-Reverte, nos explica cómo busca en la realidad lo que conoció en la ficción.

Y es en esta misma escena de los Tintínes cuando se produce el reconocimiento de Tánger por parte de Coy, algo que también forma parte del encanto y la seducción de aquélla. Se produce cuando la Tánger adulta, abismada en el álbum del inmortal héroe belga, se funde con la Tánger muchacha que la rodea, abrazada por su padre en la fotografía que está al lado de la copa de plata abollada y falta de un asa que repre-

\footnotetext{
${ }^{127}$ Ibíd., págs. 131-2.

${ }^{128}$ Arturo Pérez-Reverte, Los barcos se pierden en tierra, Madrid, Alfaguara, 2011, pág. 75.
} 
senta su primer premio en el campeonato infantil de natación. Es en aquel momento preciso cuando Coy reconoce a Tánger:

Podía comprender. No era el álbum, ni la copa de plata ni la foto, ni nada que tuviera que ver con lo que ella tenía en su memoria; pero había un punto de contacto, un territorio donde era fácil reconocerla. Quizás Tánger no era tan distinta, al fin y al cabo. Tal vez, pensó, en alguna forma también ella sea uno de los nuestros; aunque por definición cada uno de los nuestros navegue, cace, combata y se hunda solo. Barcos que pasan en la noche. ${ }^{129}$

Para Coy, la foto, la copa, los álbumes de Tintín son no sólo indicios de una vida real, sino huellas de un pasado, de «unos recuerdos no explícitos pero que sin duda sostenían el resto del tinglado y la apariencia: la niña, el soldado, los sueños y la memoria»; en la sonrisa de la niña en la foto, Coy «registraba una marcada frescura que la hacía distinta. Algo luminoso, radiante, de vida llena de posibilidades no desveladas, de caminos por recorrer, de felicidad posible y tal vez probable». ${ }^{130}$ Son las huellas que nos remiten a la patria del alma de Tánger, que quizás no sea muy distinta, en un principio, de la de muchos otros seres humanos del mundo occidental de su generación (y de la generación del autor). Y en su interpretación de esos signos, Coy le explica a Piloto, dejando entrever la ternura que siente por Tánger, que ella lucha por recuperar su infancia o la niña que fue, que lucha «por una niña que conoció hace tiempo. Una niña protegida, soñadora, que ganaba concursos de natación, que creció feliz hasta que dejó de serlo y supo que todos morimos solos... Ahora se niega a dejarla desaparecer» ${ }^{131}$ Ésta es la lucha que libra Tánger a su modo de ver, por recuperar una niña llena de vida y esperanza, de ilusión e inocencia que la vida le arrebató, por recuperar la plenitud, la integridad original perdida. Parece que lo logra en cierta medida al resucitar la historia del barco hundido y el tesoro, que será lo que le devolverá el rostro de la niña que fue, como sucede cuando el marino intuye en un momento de intimidad entre ellos que ella tenía el mismo rostro que en la foto del marco de plata, que por lo demás es el rostro que todas las mujeres tuvieron alguna vez. (Será así por lo menos mientras dure la ilusión de Coy, porque al final Tánger se revela como la verdadera sirena egoísta y despiadada que también es, y Coy comprenderá que el sueño ha sido reemplazado por «una ambición dura y neta como un trozo de piedra oscura, pulida, muy brillante»). ${ }^{132}$

\footnotetext{
${ }^{129}$ Arturo Pérez-Reverte, La carta esférica, cit., pág. 132.

${ }^{130}$ Ibíd., págs. 189-90.

${ }^{131}$ Ibíd., pág. 411.

${ }^{132}$ Ibíd., págs.261 y 453.
} 
Estas huellas son la clave, porque mediante ellas Coy no sólo identifica a Tánger, sino que llega a identificarse con ella:

Yo también sonreí así alguna vez, pensó. Y aquellos modestos objetos diseminados por la casa, la copa abollada, la fotografía de la muchacha cubierta de pecas, eran los restos del naufragio de esa sonrisa [...]. Entonces se vio desamparado, cual si fuera él y no Tánger quien sonreía en la foto con el hombre de la camisa blanca. Se reconocía en aquella imagen, y eso lo hizo sentirse huérfano, solidario, melancólico y furioso. ${ }^{133}$

Ternura y empatía conducen al reconocimiento propiciado por la sonrisa de la infancia compartida que no representa sino los sueños y la ilusión albergados en esa etapa, y desembocan en la plena identificación de Coy con Tánger. Así es como la seguirá reconociendo o se esforzará por reconocerla durante la novela, reconocimiento que entraña la restitución, la recuperación de la infancia a lo largo de $L a$ carta esférica:

Coy no pudo evitar sentirse conmovido. Seguía habiendo algo infantil, resolvió, en esa obstinada madurez, en el aplomo con que ella encaraba las consecuencias de su aventura. De nuevo la foto en el marco. De nuevo la copa de plata, la niña rodeada por el brazo protector del hombre desaparecido, la indefensión en los ojos que reían desde el umbral del tiempo donde son posibles todos los sueños. Seguía reconociéndola, a pesar de todo. O para ser más exacto, cuanto más tiempo pasaba junto a ella, la reconocía más. ${ }^{134}$

Como se explicará pocas páginas más adelante, estos sueños de la brumosa tierra natal del alma (como la llamó Fernando Savater) son los que nutren la búsqueda de Tánger; y la niña que la mujer fue, sus sueños y su aventura constituyen asimismo el verdadero tesoro que busca rescatar Coy:

En realidad el misterio del barco perdido le traía sin cuidado. Era ella, su tesón, su búsqueda, todo lo que estaba dispuesta a emprender por un sueño, lo que lo mantenía a rumbo, pese a escuchar el inequívoco rumor del mar en las rocas peligrosamente próximas. Quería acercarse a ella cuanto pudiera [...] y reconocer en ella, en la hondura de esa piel y de la carne que recubría, a la niña sonriente en la foto del marco de plata. ${ }^{135}$

\footnotetext{
${ }^{133}$ Ibíd., pág. 190.

${ }^{134}$ Ibíd., pág. 248.

${ }^{135}$ Ibíd., pág. 256.
} 
En otras palabras, el sueño infantil de Tánger es el que marca el camino que sigue Coy en el plano del horizonte, intuyendo éste que en realidad lo tiene cautivado el canto de la sirena que hará que su barco se estrelle contra las rocas, como sucede al final.

Y como anteriores personajes femeninos, Tánger Soto llegará a representar no sólo a la mujer sirena sino a todo su sexo, a la mujer a través de los siglos. ${ }^{136}$ De este modo, pensando en Tánger y otra mujer que acaba de avistar con sus lentes desde su barco, Coy deduce que «tal vez una y otra eran la misma, y la vida de los hombres gira en torno a una sola mujer: aquella donde se resumen todas las mujeres del mundo, vértice de todos los misterios y clave de todas las respuestas», ${ }^{137}$ sentencia que, a su vez, desemboca en una reflexión sobre la lucidez, el hastío, la sabiduría de las mujeres en general -simbolizadas por Penélope- a lo largo de los siglos en su relación con los hombres,

tejiendo y destejiendo tapices durante innumerables inviernos, pariendo hombres para nuevas Troyas y aguardando el retorno de héroes exhaustos; de dioses con pies de barro a los que a veces amaba, a menudo temía y casi siempre, tarde o temprano, despreciaba. ${ }^{138}$

Es la causa por la cual las mujeres «juegan con armas [...] que nosotros incluso ignoramos que existen», como razona Palermo para explicar el comportamiento de Tánger; «Son mucho más listas que nosotros. Mientras pasábamos siglos hablando en voz alta bebiendo cerveza, yéndonos a las Cruzadas o al fútbol con los amigotes, ellas estaban allí atrás, cosiendo, cocinando, observando». ${ }^{139}$ Coy descubre que Tánger se asemeja

\footnotetext{
${ }^{136}$ No creo que haga falta recordar que empleo la palabra sexo en el sentido tradicional equiparable al del anglicismo género para designar la colectividad o condición femenina o masculina (véase Manuel Seco, Nuevo diccionario de dudas y dificultades, Barcelona, Espasa, 2011).

${ }^{137}$ Es la razón por la que cuando por fin sí se acuesta con Tánger -y se adentra, por cierto, «allí donde todos los enigmas tenían su clave oculta, y donde el paso de los siglos fraguó la única verdadera tentación, en forma de respuesta al misterio de la muerte y de la vida»-, «entonces ella despertó, y con ella despertaron todas las mujeres del mundo» (ibíd., págs. 451 y 536).

${ }^{138}$ Arturo Pérez-Reverte, La carta esférica, op. cit., págs. 87-88.

${ }^{139}$ Ibíd, pág. 280. Igualmente, cuando Coy admite que quiere acostarse con Tánger, vemos cómo, de forma en apariencia natural, el pasaje pasa de la mujer concreta a la mujer en abstracto: «Quería contar todas sus pecas doradas [...]. Besarla despacio [...] poner chispas de luz y de sorpresa en sus ojos [...]. Y acechar atento en la penumbra, como un francotirador paciente, ese momento hecho de brevedad fugaz, de intensidad egoísta, en que una mujer queda absorta en sí misma y tiene el rostro de todas las mujeres nacidas y por nacer» (ibíd., pág. 106).
} 
a esas mujeres que miran desde ciertos cuadros. Miradas impasibles [...]. La certeza de que saben cosas que no dicen [...]. Arrogancia dura, sabia. Lucidez antigua [...] Penélope debía de mirar así cuando apareció Ulises veinte años después, reclamando su arco;

Todos estos atributos de la mujer universal se resaltarán reiteradamente (por ejemplo: «Ellas son distintas. Lúcidas como si la lucidez fuera una enfermedad»; «Están ahí calladas, mirándonos [...] Llevan siglos mirándonos»). ${ }^{140}$ Y Coy entiende también que el lenguaje del silencio era «un lenguaje que ella hablaba desde hacía miles de años». ${ }^{141}$ Tánger o una mujer concreta como representante de su sexo será por tanto un leitmotiv que reaparecerá a intervalos (por citar sólo los pensamientos expresados en forma de aforismo en los que desembocan determinados párrafos):

A partir de un momento, cuando se doblaba tal o cual punta de tierra y cierta parte de la vida de un hombre quedaba en franquía, una mujer, la mujer, era quizás el único motivo para mirar atrás. La única tentación posible (el artículo definido subrayado es del original);

Han sido y son todavía nuestros rehenes [...] Son malas porque se la juegan y necesitan sobrevivir. Por eso pelean a muerte, cuando lo hacen. ${ }^{142}$

En realidad, «no hay mujeres malas [...]. Igual que no hay barcos malos... Son los hombres a bordo quienes los hacen de una manera o de otra» (en una analogía de mujer y barco establecida por el Piloto, quien con su sabiduría derivada de la experiencia de la vida se pronuncia sobre varias materias). ${ }^{143}$

Esta extensa indagación en la compleja y a veces enigmática figura de la mujer -además de la añadida insondabilidad de Tánger cual sirena- que se lleva a cabo en la novela (desde el punto de vista del hombre), facilita los motivos por los cuales Coy llega a la conclusión de que «la mujer es el único ser que no puede definirse con dos oraciones consecutivas» y de que «nadie fue capaz nunca de dibujar la carta esférica que permite navegar a través de una mujer», y por los que el Piloto alerta al marino con el siguiente refrán (que por su naturaleza también sintetiza pensamiento gnómico o sentencioso): «A la mujer y al viento, con mucho tiento». ${ }^{144}$

\footnotetext{
${ }^{140}$ Ibíd., págs. 409 y 410.

${ }^{141}$ Ibíd., págs. 165 y 230.

${ }^{142}$ Ibíd., págs. 221 y 280.

${ }^{143}$ Ibíd., pág. 333.

${ }^{144}$ Ibíd., págs. 412, 481 y 507.
} 
Con todo, vamos observando que Arturo Pérez-Reverte sí se atreve a indagar en la figura de la mujer, dotándole de un muy notable protagonismo que culminará sin duda en el papel estelar del personaje de Teresa Mendoza en La Reina del Sur. $\mathrm{Y}$ aunque no voy a estudiar detenidamente este personaje en el presente trabajo, ya que se ha analizado con anterioridad -remito a los lectores al Capítulo VII de Las reglas del juego de Arturo Pérez-Reverte y a los otros estudios de esta novela y su protagonista, entre los cuales cabe destacar el de José María Pozuelo Yvancos- ${ }_{1}{ }^{145}$ cabría subrayar que esta novela, como indica su título, gira exclusivamente en torno al personaje femenino y su viaje épico, y se construye a base de los relatos arquetípicos, en primer lugar, del «viaje de ida y vuelta» («voyage and return»), es decir, la historia de transformación de un o una protagonista que emprende un viaje desde la ignorancia al conocimiento y a un nuevo y profundo entendimiento del mundo que cambia su actitud hacia la vida; en segundo lugar, la trama «de la miseria a la fortuna» («rags to riches») que gira en torno a un personaje que revela o desarrolla todo su potencial y alcanza cierta madurez; y, por último, «the quest», un protagonista llamado a partir en busca de una meta, un fin, un tesoro que en el caso de Teresa Mendoza es su supervivencia, triunfo y venganza, además de la concomitante transformación de la protagonista. ${ }^{146}$ Son tramas arquetípicas con las que se juega en $L a$ Reina del Sur, historia que asimismo detenta el carácter épico que tradicionalmente poseen tales relatos, sólo que el caso de la novela revertiana destaca por el hecho de que el protagonista es femenino, a diferencia de la tradición.

Para este ensayo, baste constatar que con la ayuda de estas maquetas de tramas arquetípicas se irá perfilando por tanto el «largo viaje de ida y vuelta» de Teresa Mendoza, como se describe explícitamente en la propia novela,,${ }^{147}$ que es también un viaje de la inocencia a la lucidez, como bien observa José Luis Ferris, ${ }^{148}$ que comienza a la edad de 23 años cuando Teresa no es sino cambiadora de pesos o cambista y la mujer de un narcotraficante de Sinaloa, México, por tanto, no más que «reposo del guerrero», hasta su ascenso social y económico y su poder e independencia, simbólicamente confirmados por su repetida presencia en la revista ;Hola! (a pesar suyo), su anagnórisis final y su vuelta a México para ajustar cuentas. Es también un viaje de aprendizaje $^{149}$ de doce años lleno de accidentes, sucesos trágicos y repentinos cam-

\footnotetext{
${ }^{145}$ José María Pozuelo Yvancos, Novela española del siglo XXI, Madrid, Cátedra, 2017, Capítulo 4.

${ }^{146}$ Christopher Booker, op. cit.

${ }^{147}$ Arturo Pérez-Reverte, La Reina del Sur, Madrid, Alfaguara, 2002, pág. 20.

${ }^{148}$ José Luis Ferris, «Mecanismos de creación, mecanismos de seducción: La Reina del Sur», en Sobre héroes y libros. La obra narrativa y periodística de Arturo Pérez-Reverte, José Belmonte y José Manuel López de Abiada, eds., Murcia, Nausicaä, 2003, págs. 97-106.

${ }^{149}$ Arturo Pérez-Reverte, La Reina del Sur, cit., págs. 56 y 93. Es un aprendizaje que empieza de forma brutal y pronto, al enterarse del asesinato de «su hombre» y ser violada por uno de los sicarios envia-
} 
bios de fortuna que alteran el rumbo del destino de Teresa Mendoza. Teresa resulta ser una de esas personas, como se observa en la novela, «cuya buena suerte se hace a base de infortunios» $;{ }^{150} \mathrm{o}$, en los términos del escueto pero ilustrativo resumen de su trayectoria que traza su abogado en una conversación con el narrador en Gibraltar, «en esta vida todo se paga [...] Lo que pasa es que algunos pagan antes, otros durante y otros después... En el caso de la Mejicana, ella había pagado antes... No le quedaba nada por perder y todo estaba por ganar. Eso fue lo que hizo». ${ }^{151}$ Teresa Mendoza es la cristalización de las posibilidades absolutas de la mujer y la culminación no sólo del trayecto desde la dependencia del hombre a la independencia y el poder total, a la liberación de todas las limitaciones impuestas por un mundo de hombres (el mundo del narcotráfico), dominado por reglas suyas, sino también de la figura de la mujer en la narrativa de Arturo Pérez-Reverte.

Puede que ninguna otra mujer revertiana llegue a alcanzar la importancia de la Mendoza, al ser la heroína de la acción, un personaje principal y «redondo», a cuyo proceso de evolución asistimos, y un «personaje individual» por su configuración compleja y sumo grado de individualidad. Pero indudablemente hay muchas otras mujeres dignas de atención y de estudio, aunque me temo que las limitaciones del presente trabajo (y de la paciencia no sólo del lector sino también del sufrido editor del presente número monográfico de la revista) no me permiten detenerme sobre sus figuras. Pero no me cabe duda de que se merecen un estudio aparte las formidables y elegantes Lolita Palma y Mecha Inzunza de El asedio y El tango de la Guardia Vieja, respectivamente; la temible, fuerte y sensual Eva Neretva de Falcó y Eva; la misteriosa y sugerente Eddie Mayo de Sabotaje, tan parecida en ciertos aspectos a Irene Adler; o la atractiva, singular, refinada, independiente y segura de sí Moira Nikolaos de Eva, que tiene algunos parentescos con la guapa, valiente y legendaria Aglae Masini rememorada en Territorio comanche, no tanto por ser griegas y man-

dos a matarla a ella también: «Ahora sabía que no podía fiarse de nadie»; es un proceso de aprendizaje duro pero sostenido que se va consolidando, con el concomitante desengaño y lucidez, cuando, por ejemplo, Teresa afirma que ningún hombre «ya nunca podría hacer que se engañara de nuevo a sí misma, creyéndose protegida del horror, del dolor y de la muerte», sensación que, en vez «de intimidarla, la acicateaba» (ibíd., págs. 59 y 134).

${ }^{150}$ Ibíd., pág. 227. En palabras del autor, «no tiene esperanza alguna y la vida le da muchos golpes, a cuál más mortal; sin embargo, paradójicamente, cada golpe, al tiempo que le arranca cosas, también la empuja hacia arriba. Cada desgracia la lleva a un estadio superior -quizá porque ella no espera nada-, y de esa paradoja se construye la existencia de Teresa» (Arturo Pérez-Reverte en Félix Linares, «La Reina del Sur. Arturo Pérez-Reverte conversa con el periodista Félix Linares», el correo digital, Bilbao, 13 de junio de 2002, servicios.elcorreo.com/aula de cultura/reverte1.html).

${ }^{151}$ Los puntos suspensivos entre paréntesis son míos; los demás son del original (Arturo Pérez-Reverte, La reina del sur, cit., pág. 228). 
cas ambas, cuanto por ser «mujeres que tienen un par», como se titula el quinto capítulo de Territorio comanche en el que se rinde homenaje a muchas de esas mujeres valientes que Arturo Pérez-Reverte conoció en las guerras y que evidentemente le han servido de inspiración para sus fuertes y formidables mujeres literarias: desde Jadranka, Maite, Heidi, Catherine Leroy «con sus cámaras al hombro, discutiendo con un soldado israelí en Tiro», Carmen Romero, Carmen Postigo, Peggy, Lola Infante, Carmen Sarmiento, Arianne, Cristina Spengler o Slobodanka «manchada de sangre, intentando cortarle la hemorragia a Paul Marchand», pasando por Aglae Masini «cruzando Beirut en el 76, esquivando francotiradores, ciega por el gas de las bombas», hasta Oriana Falacci, María la Portuguesa o Corinne Dufka. ${ }^{152}$

Todas ellas, tanto las mujeres reales como las ficticias, son mujeres singulares y no sorprende, dado el calibre de las mujeres que ha conocido en su vida Arturo Pérez-Reverte, que a la hora de plasmar sus «criaturas del aire» éstas también sean fuertes, independientes, valientes, lúcidas y atractivas en todas las acepciones de esta palabra que nos proporciona el Diccionario de la lengua española, es decir: mujeres que atraen o tienen fuerza para atraer, que ganan o inclinan la voluntad, por su gracia en el semblante o en las palabras, acciones o costumbres, y que por su físico despiertan interés y agrado. Como ha explicado Pérez-Reverte en un artículo titulado «Sobre mujeres y héroes», a la hora de escoger héroes para sus novelas, prefiere ser injusto - por rechazar a Madama Bovary o Penélope como modelos- a complaciente: quiere «lobas y no ovejas», y mujeres lúcidas, porque, en última instancia, este tipo de mujer no es nada menos que «el único personaje literario apasionanteque nos queda, el único héroe posible en el siglo XXI: soldado perdido en un territorio enemigo, de reglas hechas por los hombres. Mujeres intentando sobrevivir, llegar al mar y volver a casa. O encontrarla, al fin. Una casa propia, una vida normal. Heroínas a su pesar». ${ }^{153}$

\section{Los fantasmas del remordimiento}

En Territorio comanche se dibuja el siguiente retrato de la arriba mencionada Corinne Dufka:

recortada a contraluz en las llamas del hotel Europa, con el cabello recogido en una trenza, los ceñidos tejanos y las Nikon colgadas del cuello, el día que Barlés no pudo quedarse quieto y ella lo fotografió sacando niños en brazos. [...] Era la mujer más valiente que él

\footnotetext{
${ }^{152}$ Arturo Pérez-Reverte, Territorio comanche, Madrid, Ollero \& Ramos, 1994, págs. 112-113.

${ }^{153}$ Arturo Pérez-Reverte, «Sobre mujeres y héroes», XL Semanal, 17 de enero de 2011, www.perezreverte.com/articulo/patentes-corso/578/sobre-mujeres-y-heroes/.
} 
vio nunca en una guerra. Sus fotos de Bosnia daban la vuelta al mundo y eran portadas en Time, Paris Match y las grandes revistas internacionales. Había estado en Sarajevo meses y meses, entrado en Mostar a pie, por las montañas, y en el 92 saltó sobre una mina en Gorni Vakuf. Tardó un mes en recuperarse, y volvió de nuevo a la guerra, luciendo cicatrices aún frescas que se unían a las antiguas. Como dijo Gerva Sánchez al verla aparecer otra vez en el vestíbulo del Holiday Inn, hay mujeres que tienen un par de cojones. ${ }^{154}$

Corinne Dufka no sólo es una de aquellas mujeres valientes reales, de hecho la más valiente que Arturo Pérez-Reverte, alias Barlés, haya visto nunca, sino que en su descripción se dibujan nexos que la unen al último modelo de mujer que quisiera glosar brevemente para concluir el presente estudio. Esta figura nos proporciona ciertas pistas para empezar a trazar la génesis de un personaje revertiano, y es ejemplo de la interdiscursividad de su literatura (en este caso, si se me permite el atrevimiento de acuñar un término nuevo, la intradiscursividad o la interdiscursividad restringida, que sería la interdiscursividad que se produce entre dos o más obras del mismo autor) y del diálogo entre la realidad empírica (biográfica) y la ficción; porque Corinne Dufka tiene parentescos con el personaje de Nikon de El club Dumas y con el de Olvido de El pintor de batallas.

En aquella obra, Lucas Corso tiene unos cuantos fantasmas, porque, como vaticina Varo Borja con clarividencia, Corso es «de los que se pasan mucho rato con los ojos abiertos en la oscuridad». ${ }^{155} \mathrm{Su}$ fantasma principal es Nikon, con ese nombre de marca de cámara fotográfica (de las que colgaban varias del cuello de Corinne Dufka en la descripción que vimos arriba), «su único remordimiento»; Nikon es la fotógrafa (como Dufka) evocada que amó y con la que deseó compartir una patria común, personaje cuya huella en la novela es tan indeleble como la que dejó en el estómago de Corso - «un boquete del tamaño de un escopetazo de postas»-cuando se marchó «en busca de aquel hijo que él nunca quiso tener» y porque había llegado a considerarlo tan egoísta y «tan muerto como [s] us libros». ${ }^{156}$ La punzada de angustia por la ausencia de Nikon volverá una y otra vez a «rondar su conciencia en una ola remota, dolorosa», no dejándole olvidar los «cuatro años, un mes y doce días» que compartieron. ${ }^{157}$ Por ende, cuando en la novela se habla de la falta de rastros de vida

\footnotetext{
${ }^{154}$ Arturo Pérez-Reverte, Territorio comanche, cit., págs. 112-113.

${ }^{155}$ Arturo Pérez-Reverte, El club Dumas, cit., pág. 70.

${ }^{156}$ En esta escena evocada en El club Dumas se sugiere un dicotomía entre los libros (de Corso) -egoístas, solitarios, algunos de los cuales «ni siquiera pueden leerse porque se rompen al abrirlos»; «quien sólo se interesa por los libros no necesita a nadie»- y el cine, preferido por Nikon, -«cosa de muchos: colectivo, generoso»-; las diferencias subrayadas revelan pars pro parte, metonímicamente, las desemejanzas de carácter de los dos personajes (ibíd., págs.. 64-6, 252 y 282-3).

${ }^{157}$ Ibíd., págs. 237-8.
} 
personal en la casa de Corso - los libros y el sable exceptuados- o «de esos anclajes que todo ser humano establece, por instinto, con su memoria o su pasado», sabemos que esto obedece no tanto a que no quede huella de ese mundo en Corso - por mucho que su casa aparente que «el mundo del que procedía Lucas Corso llevaba extinguido mucho tiempo», esto no es rigurosamente cierto- cuanto a que Corso quizás busque eliminar ciertos rastros por dolorosos, ya que sí ha tenido, o dejado, algo de sí atrás. ${ }^{158}$ Por ello, pese a insistirse en la novela en que «no había estado desvalido en su vida», en que no era en absoluto desvalido, ${ }^{159}$ Corso sí tiene bastante más de desvalido de lo que parece a primera o segunda vista, principalmente por causa de Nikon, que se convertirá en el fantasma de su único remordimiento, como se deja entrever en el siguiente pasaje: «Los escasos privilegiados que lo vieron en alguno de esos rojizos atardeceres, sentado en el mirador con los ojos deslumbrados hacia poniente, turbios de ginebra holandesa, dicen que su mueca de torpe conejo desvalido parecía sincera». ${ }^{160}$ Nikon es un personaje ausente que sólo aparece evocado brevemente en la novela como una persona que una vez había formado parte de la vida de Corso y que ahora seguía presente sólo a través de los rastros de la indeleble huella que ha imprimido en la psique de Corso, en parte por su ausencia. Esa presencia fantasmal es el recordatorio del pesar, de la aflicción y del arrepentimiento. Y Nikon será un primer esbozo de una figura estructuralmente idéntica que en El pintor de batallas tendrá su pleno desarrollo.

Olvido, como Nikon, es la mujer que el protagonista masculino de la novela amó. «Joven, y tan bella que no parecía real», de una belleza «singular, esbelta, flexible», Olvido es la «causa directa» de la pintura mural que está pintando Andrés Faulques. ${ }^{161}$ Pese a una presencia discreta e indirecta en la historia (estructuralmente parecida a la de Nikon pero mayor), Olvido es un personaje complejo y redondo, con una gran riqueza psicológica, dotada también de cierta ambigüedad y capaz de sorprender, por mucho que su presencia se efectúe a base de su evocación, como en el caso de Nikon, dado que, como Nikon, ya está ausente cuando arranca le narración; de hecho, está muerta.

Faulques, el pintor de batallas del título, experimenta un dolor físico diariamente a ráfagas, síntoma de una enfermedad que también se puede leer metafóricamente como indicio del hecho de que está «acabado», como le dice más de una vez Olvido, además de como prefiguración de su muerte inminente.Todo esto hace que cada vez

\footnotetext{
${ }^{158}$ Ibíd., pág. 63.

${ }^{159}$ Ibíd, pág. 46 y 277.

${ }^{160}$ Ibíd., pág. 63.

${ }^{161}$ Arturo Pérez-Reverte, El pintor de batallas, cit., pág. 81 .
} 
duerma menos y que sus sueños sean una «duermevela incierta». ${ }^{162}$ Es un personaje bastante más atormentado que Corso por sus remordimientos.

Merece la pena detenernos sobre lo que le dice Olvido al respecto, por un lado porque se trata de una radiografía lúcida de la naturaleza de Faulques y de su trabajo y, por otro, porque recuerda claramente lo que le dice Nikon a Corso en El club Dumas, y estas dos parejas guardan parentescos notables, como estamos viendo. Olvido Ferrara es la intelectual o teórica de la relación -a diferencia de Nikon, tiene apellido, italiano, de su padre; su madre española es responsable de su nombre que resulta irónico ya que es un personaje inolvidable para Faulques-. Es en extremo perspicaz, como hemos visto que lo son todas las mujeres revertianas, y «única para colocar aquí y allá pensamientos ajenos a modo de reflexiones espontáneas o sentencias propias», como hace el propio Pérez-Reverte a lo largo de la novela. ${ }^{163}$ Olvido «llegó demasiado tarde a un mundo demasiado viejo», le dice al pintor la abuela de Olvido, emparentándola de este modo a través de la cita intertextual del poeta y dramaturgo francés Alfred de Musset con la estirpe de héroe cansado que es también Jaime Astarloa - es la divisa de éste-; ya no hay mujeres como la que ella quería ser, nos explica ella misma. ${ }^{164}$

Por cierto, la abuela materna de Olvido, Lola Zegrí, una octogenaria cuya atractiva elegancia forma parte de su supervivencia de otro mundo, como la septuagenaria Duquesa del Nuevo Extremo Cruz Bruner de La piel del tambor; es otro personaje femenino fascinante y por menor no menos sugerente; fue alumna de la última época del Bauhaus, amiga de Duchamp, Braque, Picasso y Renoir -tuvo un papel en La regla del juego [La règle du jeu, 1939] de Renoir, junto a Henri Cartier-Bresson, tal como se nos informa en la novela en una clave intertextual; la propia novela de Pérez-Reverte hubiera podido titularse así-. Fue habitante de ese mundo de la primera mitad del siglo XX que el escritor luego recreará en la serie Falcó y en Sabotaje en especial. Estas elegantes mujeres mayores, supervivientes de otros tiempos que todavía conservan una belleza ya antigua, revelan la fascinación del autor también por esta clase de mujer que encierra las huellas de un viejo mundo, ahora en decadencia, y una nostalgia por esos mundos extinguidos tan característica de Arturo Pérez-Reverte; forman parte de una clase de mujer homenajeada no sólo en algunas de sus novelas, sino también en artículos tales como «Una conversación», que nos

\footnotetext{
${ }^{162}$ Ibíd., pág. 9.

${ }^{163}$ Ibíd., págs. 86 y 180.

${ }^{164}$ Ibíd., págs. 81-83 y 178.
} 
hablan de esas mujeres que han «sobrevivido razonablemente los estragos de la vida [...] con la coquetería depurada en una larga vida de elegancia y belleza». ${ }^{165}$

Con una familia relacionada con el mundo de la pintura desde hacía generaciones, Olvido cursó estudios de Historia del Arte, y fue modelo fotográfico, «hasta que decidió pasar al otro lado de la cámara», trabajando primero para revistas caras, antes de convertirse en la «turista del desastre» y «alumna voluntariosa» que acompañará a Faulques por la guerra, después de conocerlo en un museo - un encuentro descrito como fruto de las reglas ocultas que determinan casualidades-, siguiendo sus indicaciones y las reglas para moverse por territorio hostil, porque era consciente de haber vivido en un mundo ficticio desde niña y quería valerse de la cámara como su «pasaporte a lo real: allí donde las cosas no pueden ser embellecidas con estupidez, retórica o dinero». ${ }^{166}$ Lo que le llega a decir a Faulques prefigura las distintas muertes de ambos:

Fotografías a la gente buscando las rectas y curvas que la matarán [...]. Fotografías las cosas buscando los ángulos por donde empezarán a desmoronarse. Vas a la caza de cadáveres y ruinas adivinados, prematuros. A veces pienso que me haces el amor con esa desesperación desolada y violenta porque al abrazarme sientes el cadáver que seré un día, o que seremos ambos. Estás acabado a medio plazo, Faulques. Empiezas a dejar de ser un soldado callado y flaco. No lo sabes, pero has contraído el virus que terminará impidiéndote hacer tu trabajo. Un día te llevarás la cámara a la cara, y al mirar por el visor sólo verás líneas, volúmenes y leyes cósmicas. Espero no estar a tu lado en ese momento, porque te volverás insoportable, de puro autista: un arquero zen que ejecuta movimientos en el aire con las manos vacías. ${ }^{167}$

Esto, como el lector de la novela descubre, es precisamente lo que le acaba sucediendo a Faulques y la razón por la que deja la fotografía y opta por la pintura. La muerte de Olvido, al pisar una mina, mientras Faulques, fascinado observador de su movimiento en los instantes previos visto a través del prisma de líneas y recuadros de ajedrez, tarda demasiado en avisarla, será su gran remordimiento. ${ }^{168}$ En El club Dumas, Nikon planea sobre la novela como un fantasma a través de los recuerdos de Corso -de hecho, se habla del fantasma de Nikon explícitamente-; ${ }^{169}$ y Olvido se

\footnotetext{
${ }^{165}$ Arturo Pérez-Reverte, «Una conversación», XL Semanal, 15 de octubre de 2018, www.zendalibros. com/una-conversacion/.

${ }^{166}$ Ibíd., págs. 79, 82, 184 y 189-90.

${ }^{167}$ Ibíd., págs. 124-5.

${ }^{168}$ Ibíd., págs. 283 y 297.

${ }^{169}$ Arturo Pérez-Reverte, El club Dumas, cit., págs. 65-66.
} 
desvanece en su propio reflejo en la única imagen fotográfica que de ella conserva el pintor. ${ }^{170}$

Olvido y Nikon, las mujeres amadas y ausentes, prefiguradas en la literatura revertiana por la figura de Claire Zimmerman dibujada con pocas pinceladas en $E l$ húsar, son el principal y único remordimiento de los protagonistas masculinos de las respectivas novelas; inspiradas sin duda en Corinne Dufka, Olvido y Nikon se dedican a la fotografía (en el caso de éstas en blanco y negro); Olvido y Nikon intuyen que algo en sus parejas se ha muerto, y las dejan, aunque por razones distintas: «Estás muerto como tus libros», zanja Nikon; «Jamás quisiste a nadie, Corso. Esa fue la primera y última vez que ella pronunció sólo su apellido; la primera y última vez que le negó su cuerpo, antes de marcharse para siempre. En busca de aquel hijo que él nunca quiso tener». ${ }^{171} \mathrm{Y}$ ya vimos arriba lo que le dice Olvido a Faulques antes de morirse. Efectivamente, como vaticina Olvido, Faulques, como Corso, se tornará un frío arquero zen -o también, como algún que otro personaje revertiano de novelas anteriores, un samurái que practica bushido, en otra analogía-, ${ }^{172}$ que es, por cierto, cómo el fotógrafo francés Henri Cartier-Bresson, traído más de una vez a colación en El pintor de batallas en los pasajes sobre fotografía, se describía a sí mismo. ${ }^{173}$ Pero todo arquero zen, por frío que busque ser, tiene sus remordimientos. Nikon, Olvido y en menor medida Claire, serán los lúcidos fantasmas de esos remordimientos que evocarán de forma velada una plenitud fugaz, disfrutada sólo temporalmente en un momento siempre pasado. Esas mujeres demuestran lo que se dice también en $\mathrm{El}$ maestro de esgrima: que «era imposible no encontrar una sombra agridulce de mujer en la memoria de cualquier hombre». ${ }^{174}$

En comparación con la talla de las mujeres revertianas que hemos visto, no creo que sea injusto concluir que los personajes masculinos son francamente seres inferiores; aunque quizás ellos y los hombres en general no sean exactamente estúpidos (o no siempre o no del todo ni en todos los casos), como le espeta Eddie Mayo a Falcó en un momento determinado en Sabotaje: «-Ustedes, los hombres, y su absurda seguridad -rió entre dientes, sin ganas-. Sus extraños códigos de grupo los vuelven

\footnotetext{
${ }^{170}$ Arturo Pérez-Reverte, El pintor de batallas, cit., pág. 181.

${ }^{171}$ Arturo Pérez-Reverte, El club Dumas, cit., pág. 66.

${ }^{172}$ Arturo Pérez-Reverte, El pintor de batallas, cit., pág. 183. Un «samurái hosco y solitario, que se bastara a sí mismo sin necesitar un solo amigo en el mundo» es como Barlés describe a su compañero Márquez en Territorio comanche (Arturo Pérez-Reverte, Territorio comanche, cit., pág. 73); los mismos términos se podrían emplear para describir a Faulques.

${ }^{173}$ Cartier-Bresson decía que el fotógrafo ha de convertirse primero en el blanco para poder dar de lleno en él (citado en Susan Sontag, On Photograpy, Londres, Penguin, 1977, pág. 116).

${ }^{174}$ Arturo Pérez-Reverte, El maestro de esgrima, cit., pág. 43.
} 
estúpidos». ${ }^{175}$ Lo que sí se ve a lo largo de la literatura revertiana, como le subraya Nino Palermo a Coy en La carta esférica, es que las mujeres son más listas que los hombres. Pero no se trata sólo de eso. Como reconoce el propio Falcó en Sabotaje pensando en Eva Neretva (o Rengel), y haciéndose también eco de algunas ideas del propio autor expuestas a lo largo de este artículo, las mujeres de su tiempo son simplemente superiores al hombre, algo que se refleja una y otra vez en las heroínas singulares, lúcidas, complejas y de armas tomar de Arturo Pérez-Reverte:

En aquel tiempo, se dijo, a diferencia de otros aún recientes, sobrevivían las hembras más duras, inteligentes y tenaces. Se veían filtradas por pruebas nuevas. La Historia, acelerada en su modernidad, imponía una selección natural donde la mujer, sin duda, emergía como nueva heroína del siglo. Ellas hacían cosas que nunca habían hecho antes, y las abordaban con más disciplina, con más fe, con más crueldad, incluso, que los propios hombres. Tal vez porque aún no habían tenido tiempo de construirse una retaguardia, y lo sabían. Para ellas, en esa fase todavía peligrosa, derrota equivalía a aniquilación. La debilidad, la piedad, eran lujos que no podían permitirse. Y quizá las supervivientes, las que viesen amanecer tras la noche negra que se extendía por Europa y el mundo viejo, fuesen la verdadera raza superior, después de todo. El futuro. ${ }^{176}$

Efectivamente, las mujeres, como espero que hayamos tenido la ocasión de observar, tal como son vistas y representadas en la literatura revertiana, llegan a ser una raza superior.

\footnotetext{
${ }^{175}$ Arturo Pérez-Reverte, Sabotaje, cit., pág. 176.

${ }^{176}$ Ibíd., pág. 125.
} 